IZA DP No. 9207

Building Trust in Rural Producer Organizations in Senegal:

Results from a Randomized Controlled Trial

Tanguy Bernard

Markus Frölich

Andreas Landmann
Pia Naima Unte

Angelino Viceisza

Fleur Wouterse

July 2015 


\title{
Building Trust in Rural Producer Organizations in Senegal: Results from a Randomized Controlled Trial
}

\author{
Tanguy Bernard \\ IFPRI and University of Bordeaux IV \\ Markus Frölich \\ University of Mannheim and IZA \\ Andreas Landmann \\ University of Mannheim
}

\author{
Pia Naima Unte \\ University of Mannheim
}
Angelino Viceisza
Spelman College

Fleur Wouterse

IFPRI

Discussion Paper No. 9207
July 2015

\author{
IZA \\ P.O. Box 7240 \\ 53072 Bonn \\ Germany \\ Phone: $+49-228-3894-0$ \\ Fax: +49-228-3894-180 \\ E-mail: iza@iza.org
}

\begin{abstract}
Any opinions expressed here are those of the author(s) and not those of IZA. Research published in this series may include views on policy, but the institute itself takes no institutional policy positions. The IZA research network is committed to the IZA Guiding Principles of Research Integrity.

The Institute for the Study of Labor (IZA) in Bonn is a local and virtual international research center and a place of communication between science, politics and business. IZA is an independent nonprofit organization supported by Deutsche Post Foundation. The center is associated with the University of Bonn and offers a stimulating research environment through its international network, workshops and conferences, data service, project support, research visits and doctoral program. IZA engages in (i) original and internationally competitive research in all fields of labor economics, (ii) development of policy concepts, and (iii) dissemination of research results and concepts to the interested public.
\end{abstract}

IZA Discussion Papers often represent preliminary work and are circulated to encourage discussion. Citation of such a paper should account for its provisional character. A revised version may be available directly from the author. 


\section{ABSTRACT}

\section{Building Trust in Rural Producer Organizations in Senegal: Results from a Randomized Controlled Trial ${ }^{*}$}

Trust is crucial for successful collective action. A prime example is collective commercialization of agricultural produce through producer organizations. We conduct a cluster-randomized controlled trial in rural Senegal in which we vary the number and the type of smallholder farmers - members and/or leaders of local producer organizations - invited to a three-day training on collective commercialization. We use this variation to identify effects on intra-group trust, both direct treatment effects of having participated in the training and spillover effects on farmers who did not partake. Looking at different measures of trust in leaders' competence and motives and of trust in members we find that participating in the training significantly enhances both trust in leaders and trust in members. For trust in leaders, we also find a strong spillover effect. Our findings suggest that relatively soft and non-costly interventions such as a group training appear to be able to positively affect trust within producer organizations.

JEL Classification: D71, O12, Q13

Keywords: rural producer organizations, smallholder farmers, trust, Senegal

Corresponding author:

Markus Frölich

University of Mannheim

L7, 3-5

68131 Mannheim

Germany

E-mail: froelich@uni-mannheim.de

\footnotetext{
* We gratefully acknowledge financial support from the German Federal Ministry for Economic Cooperation and Development through the funding initiative for International Agricultural Research Centers and from the International Food Policy Research Institute Mobile Experimental Economics Laboratory. We are also grateful to FONGS, GRET and PINORD for a fruitful collaboration. We acknowledge valuable comments of participants at the 2015 Development Economics Network Workshop, Berlin, and at the 2015 Conference on Development Economics, Kiel. Shaikh Tanvir Hossain and Katrin Reich provided excellent research assistance.
} 


\section{Introduction}

Rural Producer Organizations (RPOs) ${ }^{1}$ can provide smallholders in developing countries with better access to input and output markets (Markelova et al., 2009, Rondot and Collion, 2001; The World Bank, 2008). Acting collectively within RPOs is often seen as an effective means to reduce transactions costs, to gain bargaining power, to obtain necessary market information, and to get access to new technologies and high value markets (Devaux et al., 2009; Poulton et al., 2010; Stockbridge et al., 2003). While examples of successful collective action exist, such as coffee production, grading and export in Ethiopia (Kodama, 2007), green bean exports in Kenya (Narrod et al., 2009) and cotton production and exports in Mali (Tefft, 2004), many RPOs in developing countries struggle to offer the type of services that would lead to higher output prices for their members (Bernard et al., 2008a, 2010; Fafchamps and Hill, 2005; Markelova et al., 2009). Instead of commercializing their produce collectively, smallholders frequently opt for selling it individually to traders at the farmgate (Fafchamps and Hill, 2005).2

Whether collective commercialization takes place or not is highly correlated with the ability to coordinate and the prevalence of trust ${ }^{3}$ within a RPO (Hill et al., 2014; Shiferaw et al., 2011). Mistrust between farmers can even lead to the disintegration of RPOs (Masakure and Henson, 2005). Typically, RPOs are member-driven organizations whose success depends on their members' participation in joint activities. Reasons for members being reluctant to participate in collective commercialization largely play out at the intra-RPO level (Bernard and Wouterse, 2015). First, farmers may struggle with liquidity constraints and hence

\footnotetext{
1 "Producer organizations are membership-based organizations or federations of organizations with elected leaders accountable to their constituents. They take on various legal forms, such as cooperatives, associations, and societies" (The World Bank, 2008, p. 154). In this paper, we analyze farmer groups in Senegal that provide members with services. Hence, they differ from NGOs which also provide services to non-members (Bernard and Wouterse, 2015).

${ }^{2}$ This paper implicitly builds on the assumption that collective commercialization is more efficient than individual marketing. See, for example, Bernard et al. (2008b) for evidence that cooperatives' members achieve higher prices for their produce than non-members in Ethiopia, Shiferaw et al. (2008) for evidence that collective commercialization achieves higher output prices than individual sales to traditional buyers in Kenya, and Wollni and Zellner (2007) for evidence that commercialization through cooperatives achieves higher output prices in Costa Rica. See Section 2.2 for details about prices achieved by farmers in our sample.

${ }^{3} \mathrm{We}$ define trust as "a particular level of the subjective probability with which an agent assesses that another agent or group of agents will perform a particular action" (Gambetta, 2003, p. 277) and hence do not regard it as being a form of social capital in itself, but rather as being a measurable link between social capital and collective action (Ostrom and Ahn, 2003).
} 
decide against participating in collective commercialization as it involves substantial delays in payment as compared to individual farmgate sales (Fafchamps and Hill, 2005). Second, farmers need to have sufficient trust in their leaders' motives and competences. The sales processes of collective commercialization are typically executed by few leaders and are not transparent for members. Members may fear to not be paid at all or that price increases that occur through bulking will not be shared with them fairly (Buck and Alwang, 2011; Hill et al., 2014). Third, a farmer's decision to participate in collective commercialization is likely to be affected by her belief about the behavior of fellow farmers. Trust in fellow members' and their commitment is needed to believe that the minimum number of produce will be reached for bulk sales and, hence, to decide to participate (Bernard et al., 2014).

According to the theoretical framework provided by Ostrom and Ahn (2003), success and failure of collective action is determined by a complex configuration of various forms of social capital-trustworthiness $\bigsqcup^{4}$, networks and institutions 5 - which enhance trust. Trust is seen as the core link between social capital and collective action. It reduces opportunistic behavior and transaction costs (Collier, 2002; Ostrom and Ahn, 2003; Putnam, 1993). "Trust lubricates cooperation" (Pretty and Ward, 2001, p.211). We expect that a training intervention can strengthen existing horizontal and vertical networks and may even create new ones through repeated interaction of farmers. We further expect a training intervention to clarify the process of collective commercialization and the rules involved and, thus, to create a common understanding of the relevant institutions. We hypothesize that such increases in social capital will lead to a positive effect of a training intervention on trust in members and on trust in leaders.

We conduct a cluster-randomized controlled trial to test these hypotheses in the context of RPOs in Senegal. We randomly invited members and/or leaders to participate in a three-day training to build social capital in order to induce members and leaders to coordinate towards successful collective commercialization. The training itself consisted of three days of interactive discussion on the benefits, conduct and constraints of collective commercialization and was executed in

\footnotetext{
${ }^{4}$ The term trustworthiness refers to intrinsic motivation as an independent reason for behaving cooperatively (Ostrom and Ahn, 2003).

${ }^{5}$ Institutions are the rules of the game that people devise (North, 1990). They specify which actions and outcomes are required, prohibited, or permitted, and which sanctions are authorized (Ostrom and Ahn, 2003).
} 
collaboration with GRET (a French NGO) and PINORD (a Senegalese NGO). In all treated RPOs, a general assembly was convened shortly after the training to discuss its content with non-participants. All participating RPOs had stated collective commercialization as one of their main objectives despite facing important difficulties in aggregating their members' produce ${ }^{6}$

We assess how this intervention affects trust in a sample of 798 smallholder farmers from 73 RPOs. We analyze both intention-to-treat effects, i.e., the treatment effect of the invitation to participate in the training, and treatment effects of the training itself. Our main outcome variables of interest are survey measures of trust in leaders' competence and motives and survey measures of trust in members (Twyman et al., 2008). We distinguish between trust in leaders' integrity, informational advantage, efficiency and negotiation skills, and general and farming-specific trust in members.7 In each RPO we randomly varied the number of members and leaders invited to the training and interviewed both invited and non-invited individuals. This enables us to analyze (i) the average treatment effect of whether or not a RPO was selected for training, (ii) the direct treatment effect of whether or not an individual was selected for training, and (iii) the spillover effect on non-treated individuals in treated RPOs.

Our results suggest a positive treatment effect of the training on measures of both trust in leaders and trust in members. For trust in leaders, the effect is especially pronounced for trust in their integrity and their informational advantage. Moreover, results suggest a strong spillover effect on trust in leaders of non-treated members, i.e., that the sizable positive average treatment effect is not to be attributed solely to personal treatment. The spillover effect is especially pronounced for trust in leaders' integrity and their negotiation skills. We show that while RPOs may face several constraints with respect to coordination towards collective commercialization, a relatively simple and non-costly group training may contribute to a substantial change in trust in leaders and trust in members and, thus, to clearing a barrier to collective commercialization and other collective endeavors. Social capital is often thought to increase with use, thus, the training may well have been the starting point for more collective endeavors to come 8

\footnotetext{
${ }^{6}$ See Section 3 for details on the training intervention and the sample.

${ }^{7}$ See Section 4.2 for details on the measures of trust.

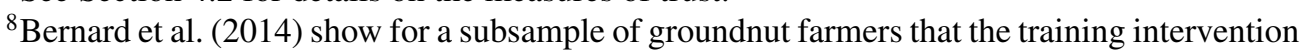
indeed had a positive effect on the quantity of produce commercialized collectively through the RPOs.
} 
The remainder of this paper is organized as follows: We begin, in Section 2. by describing the institutional background of RPOs in Senegal and the issues with collective commercialization through such organizations. In Section 3, we describe the cluster-randomized controlled trial. In Section 4, we develop the hypotheses tested in this paper and describe our measures of trust. In Section 5 , we present our empirical strategy and estimates of the treatment effects on RPOlevel and, in Section 6, on individual level. We conclude in Section 7 .

\section{Background: RPOs in Senegal}

\subsection{Institutional setting}

Seven out of ten rural households in Senegal are members of RPOs, and RPOs have expanded rapidly in number and membership in the last decades. Between 1982 and 2002, the percentage of villages with RPOs rose from 8 to 65 percent in Senegal (The World Bank, 2008). Senegal is a country with a vast array of rural institutions in thousands of villages and with strong national-level organizations (Bernard and Wouterse, 2015).

The history of agricultural and development policy in Senegal since independence can be divided into two main periods: two decades of state intervention followed by two decades of liberalization. Like in many other developing countries, the Senegalese government initiated cooperatives in the 1960s which primarily dealt with the commercialization of groundnuts. The entire value chain of agricultural production of groundnuts and cotton was organized and controlled by state entities such as producer cooperatives that were in charge of providing extension, inputs and credit to farmers as well as of collecting, processing and exporting output. Farmers typically considered cooperatives as an extended arm of the government rather than as an organization that they owned. Support of the international community led to the creation and development of regional organizations for rural development which aimed at specializing and transforming agricultural systems in the different agro-ecological zones. However, these organizations focused on the cultivation of a particular type of crop which was in contrast to the reality of rural smallholders typically cultivating several types of crops (Bernard et al., 2014; Bernard and Wouterse, 2015).

In the 1970s, this system of rural development went into crisis. Throughout 
the country, farmers founded the first independent farmers' organizations to represent their own interests. In 1978, the Federation of Senegalese NGOs (FONGS) was established to reinforce solidarity and communication among farmer groups, to foresee their training needs and to interact with the outside world on their behalf. Foreign stakeholders became increasingly interested in farmers' organizations as partners for development projects. In the 1980s, the new agricultural policy which followed the near bankruptcy of the country and a bail-out deal by the International Monetary Fund advocated the complete withdrawal of the state from agriculture. Consequently, the government facilitated the emergence of a new category of organizations with a more flexible legal status. These groups grew rapidly due to the support of their creation and their preferential treatment for obtaining credit. To defend its own interests, FONGS undertook ambitious projects at the national level such as cereal banks. In 1993, FONGS initiated the creation of a platform (CNCR) consisting of seven national federations of farmers, livestock producers, fishermen, horticultural producers and rural women. Its objective was to promote dialogue and the exchange of experience between its members, to encourage pooling of resources and competences and to serve as voice for the farmer movement versus the state and donors. In 1995, two other federations joined bringing the platform's total number of members up to about 3 million rural dwellers. In 1996, an NGO (ASPRODEB) was founded that could disburse funds of various donors and offer services to rural producers (Bernard et al., 2014, Bernard and Wouterse, 2015; Mercoiret, nd; Réseau des Organisations Paysannes et Pastorales du Sénégal, 2008; The World Bank, 2008).

The role, functioning and capacity of RPOs has changed significantly with the gradual liberalization of the agricultural sector. They have evolved towards independent member-controlled entities capable of dealing with various kinds of partners. Yet, these RPOs face new challenges in ensuring the commitment of members. This is particularly true for activities related to collective commercialization of agricultural output. In fact, while RPOs remain active in input and credit provision, their capacity to aggregate output has been weakened considerably. At time of harvest, producers are now visited by private collectors and traders. This has led to important side-selling, produce is not marketed solely through the RPOs. As a result, RPOs are seldom able to aggregate the necessary amount of produce to trigger economies of scale and bargaining power at time of commercialization. This is despite isolated evidence that RPOs in Senegal can 
in fact provide their members with profitable and reliable output commercialization services. In sum, in the absence of a sufficient amount of aggregated output, RPOs are not in a position to effectively obtain higher output prices which leads to further side-selling and a lack of interest of members for commercialization services offered by these organizations (Bernard et al., 2014).

\subsection{Collective action in Senegalese RPOs}

Generally, problems of collective action arise "whenever individuals face alternative courses of actions between short-term self-regarding choices and one that, if followed by a large enough number of individuals in a group, benefits all" (Ostrom and Ahn, 2003, p. xiv). In the context of commercialization of agricultural produce, farmers who are organized in RPOs can choose between selling their produce directly at the farmgate to a local trader with immediate payment and selling it collectively through their RPO. Farmers in our sample cultivate either groundnuts, rice, or onions as their main crop 9 While groundnut farmers primarily sell their groundnuts either individually or collectively for private gains, onion farmers have been observed to engage in joint collection and commercialization of firewood. Rice farmers use part of their gains from selling their rice (privately or collectively) for financing irrigation systems.

For collective commercialization of any type of produce, the RPO's leaders will typically negotiate with a contract buyer who offers a higher price than the local traders if a minimum amount of produce is sold. This quantity is typically too large to be reached by just one individual farmer such that complying with the contract requires coordination among the members of the RPO. Moreover, these contracts tend to be rather discrete in the sense that they are void if a certain threshold of aggregated produce is not met and payments are usually made some time after the farmers delivered their produce to the RPO for collective commercialization (Bernard et al., 2014). In our sample, two thirds of the farmers who report to have sold to traders in the 2010/2011 agricultural season (March 2010 to March 2011) state that they received the payment on the day of the transaction while only one quarter of the farmers who sold through the RPO report to have received the payment on the day the transaction took place.

Senegalese RPOs appear to be facing significant constraints when it comes

\footnotetext{
${ }^{9}$ There is no heterogeneity within any RPO in our sample regarding the main crops cultivated by members and leaders.
} 
to collective action in the form of collective commercialization of agricultural produce. Although RPOs in our sample were selected based on collective commercialization being one of their main objectives, only roughly one third of the RPOs in our sample report to have engaged in collective commercialization in the 2010/2011 agricultural season. $4^{10}$ On average, farmers who sold their produce through the RPO in the 2010/2011 season achieved higher prices per kilogram than those who sold their produce individually. Only one quarter of the farmers who sold their produce individually to local traders regularly dealt with the same traders. When asked about difficulties faced when selling their produce individually, only 20 percent of the respondents indicated that there were no major problems. For the remaining respondents, the main issue was lack of transportation means to reach more lucrative markets (cited by 48 percent) followed by insufficient visits by potential buyers (17 percent), lack of knowledge about current prices (15 percent) and lack of sufficient quantity of produce to be able to negotiate a better price ( 8 percent).

While lack of financial means and technical capacities at the RPO level are likely to be significant constraints to collective commercialization, members' perception of collective commercialization and issues of coordination between members also seem to represent important constraints, independent of the type of crop to be sold collectively. Leadership has been shown to be a key element of successful coordination within RPOs (Agrawal, 2001; Bernard and Wouterse, 2015; Markelova et al. 2009). 11 On the one hand, leaders need to have the necessary skills for the collective marketing and relevant links to outsiders. On the other hand, members need to trust their leaders (Arcand, 2002; Markelova et al., 2009). In those RPOs that engaged in collective commercialization, only 44 percent of the farmers delivered part of their produce to the RPO to be sold collectively. Respondents state three main reasons for why they chose to sell individually in spot market-like transactions to local traders rather than collectively through their RPO: most find collective commercialization to be too risky (without specify-

\footnotetext{
${ }^{10}$ We consider a RPO to be engaged in collective commercialization if at least one farmer sold his or her main produce (groundnut, onion, or rice) through the RPO.

${ }^{11}$ A commonly found organizational structure in Senegalese RPOs involves a relatively circumscribed sub-group of members bearing more responsibilities and more influence than others. Leadership status is often associated with traditional social roles (Arcand, 2002).
} 
ing the exact nature of this risk).$^{12}$ some do not believe that it offers them a better price then selling individually, and to others collective commercialization appears to be a complicated process that takes up too much time 13

RPOs engaging in collective commercialization differ significantly from those who did not engage in collective sales in the 2010/2011 agricultural season (see Table 1).14 Their members are younger, own more motorcycles, are more likely to have savings accounts with banks and MFIs, and have larger fields. They cultivate groundnuts and rice more often than onions. Moreover, we find significantly higher average trust levels in RPOs that engaged in collective commercialization than in those that did not.

Farmers who contributed part of their produce to collective commercialization in the season prior to the baseline data collection appear to be significantly more trusting than those who did not contribute (see Table 2). Moreover, they are more likely to be literate than those who did not contribute, less likely to be a member, less likely to be related to a leader, more likely to have a savings account, have larger fields and more motorcycles, and are younger. They are also more likely to come from ethnically heterogeneous RPOs, have been members of their RPO for a shorter time period, are more likely to be cultivating groundnuts and less likely to be cultivating onions. Looking at different measures for trust, we find a significantly positive pairwise correlation between several trust measures and an indicator for whether a RPO engaged in collective commercialization. Similary, we find a significantly positive pairwise correlation between several trust measures and individual participation in collective commercialization (see Table 3).

\footnotetext{
${ }^{12}$ The risk inherent in collective commercialization may be categorized into two types of risk: the price risk associated with freely working markets and the risk associated with being dependent on others' behavior. On the intra-RPO level, the outcome of collective commercialization depends on the number of fellow farmers who participate as well as the competence and behavior of the leaders involved in the transactions.

${ }^{13} 50$ percent of the respondents stated risk as a reason, 30 percent the price and 26 percent the inconvenience (numbers do not add up to 100 percent as answers were given in free text and each person could provide several reasons). Information on this question is only available for a subsample of groundnut farmers.

${ }^{14}$ See Appendix A for a definition of all variables used in the empirical analysis.
} 
Table 1: Descriptive statistics by collective commercialization activity on RPO level (RPO characteristics and RPO averages of individual characteristics)

\begin{tabular}{|c|c|c|c|c|c|}
\hline Variable & $(\mathrm{N}=69)$ & $\begin{array}{l}\text { Standard } \\
\text { deviation }\end{array}$ & $\begin{array}{l}\text { Mean if RPO not } \\
\text { active in collective } \\
\text { commercialization } \\
\quad(\mathrm{N}=49)\end{array}$ & $\begin{array}{l}\text { Mean if RPO } \\
\text { active in collective } \\
\text { commercialization } \\
\qquad(\mathrm{N}=20)\end{array}$ & Difference \\
\hline \multicolumn{6}{|l|}{ trust outcomes } \\
\hline efficiency & 0.69 & 0.22 & 0.66 & 0.77 & $-0.11^{*}$ \\
\hline farming & 0.64 & 0.21 & 0.62 & 0.69 & -0.08 \\
\hline general & 0.62 & 0.23 & 0.59 & 0.70 & $-0.11^{*}$ \\
\hline information & 0.70 & 0.21 & 0.67 & 0.78 & $-0.11^{* *}$ \\
\hline integrity & 0.70 & 0.22 & 0.68 & 0.77 & -0.09 \\
\hline negotiation & 0.64 & 0.21 & 0.61 & 0.71 & $-0.10^{*}$ \\
\hline trust_factor & -0.04 & 0.50 & -0.11 & -0.15 & $-0.26^{*}$ \\
\hline trust_sum & 3.99 & 1.18 & 3.82 & 4.42 & $-0.61^{*}$ \\
\hline \multicolumn{6}{|l|}{ additional covariates } \\
\hline $\operatorname{age}^{a}$ & 55.50 & 10.44 & 57.33 & 51.16 & $6.18^{* *}$ \\
\hline bicycles & 0.17 & 0.25 & 0.14 & 0.22 & -0.07 \\
\hline distance to market & 10.38 & 29.71 & 11.49 & 7.68 & 3.81 \\
\hline distance to storage $\mathrm{e}^{b}$ & 11.94 & 18.56 & 12.08 & 11.58 & 0.51 \\
\hline groundnut & 0.41 & 0.49 & 0.31 & 0.65 & $-0.34^{* * *}$ \\
\hline hectares ${ }^{b}$ & 3.56 & 2.88 & 2.91 & 5.30 & $-2.40^{* * *}$ \\
\hline heterogeneity & 0.36 & 0.48 & 0.31 & 0.50 & -0.19 \\
\hline household size ${ }^{b}$ & 12.71 & 4.09 & 12.58 & 13.05 & -0.46 \\
\hline literate $^{b}$ & 0.42 & 0.31 & 0.40 & 0.47 & -0.08 \\
\hline male & 0.42 & 0.29 & 0.41 & 0.46 & -0.06 \\
\hline member & 0.79 & 0.15 & 0.81 & 0.75 & 0.06 \\
\hline members' initiative & 0.30 & 0.25 & 0.30 & 0.33 & -0.03 \\
\hline motorcycles & 0.16 & 0.21 & 0.13 & 0.23 & $-0.10^{*}$ \\
\hline onion & 0.46 & 0.50 & 0.61 & 0.10 & $0.51^{* * *}$ \\
\hline phone & 0.95 & 0.07 & 0.94 & 0.96 & -0.02 \\
\hline related to leader ${ }^{b}$ & 0.63 & 0.35 & 0.64 & 0.60 & 0.04 \\
\hline rice & 0.13 & 0.34 & 0.08 & 0.25 & $-0.17^{*}$ \\
\hline savings in bank & 0.13 & 0.15 & 0.10 & 0.21 & $-0.11^{* * *}$ \\
\hline savings in MFI & 0.32 & 0.18 & 0.28 & 0.40 & $-0.12^{* * *}$ \\
\hline $\operatorname{size}^{a}$ & 31.83 & 8.28 & 31.73 & 32.05 & -0.32 \\
\hline vehicles & 0.09 & 0.19 & 0.09 & 0.12 & -0.03 \\
\hline year of creation ${ }^{a}$ & 1996.70 & 10.30 & 1996.40 & 1997.42 & -1.02 \\
\hline year joined ${ }^{b}$ & 1999.53 & 7.54 & 1999.54 & 1999.49 & 0.05 \\
\hline
\end{tabular}

Notes: Information on collective commercialization in the 2010/2011 season is only available for 69 out of 73 RPOs. We report averages and standard deviations in the sample of 69 RPOs, averages in the subsamples of RPOs that did and did not engage in collective commercialization in the 2010/2011 season and results of two-sample t tests with the null of equal means in RPOs not having engaged and having engaged in collective commercialization.

${ }^{a}$ Information on these variables is only available for 64 out of 69 RPOs of which 45 did not engage in collective commercialization in the 2010/2011 season and 19 did.

${ }^{b}$ Information on these variables is only available for 62 out of 69 RPOs of which 45 did not engage in collective commercialization in the $2010 / 2011$ season and 17 did.

${ }^{*} p<0.10,{ }^{* *} p<0.05,{ }^{* * *} p<0.01$ 
Table 2: Descriptive statistics by collective commercialization activity on individual level

\begin{tabular}{|c|c|c|c|c|c|}
\hline Variable & $(\mathrm{N}=538)$ & $\begin{array}{l}\text { Standard } \\
\text { deviation }\end{array}$ & $\begin{array}{l}\text { Mean if farmer not } \\
\text { active in collective } \\
\text { commercialization } \\
\qquad(\mathrm{N}=467)\end{array}$ & $\begin{array}{l}\text { Mean if farmer } \\
\text { active in collective } \\
\text { commercialization } \\
\quad(\mathrm{N}=71)\end{array}$ & Difference \\
\hline \multicolumn{6}{|l|}{ trust outcomes } \\
\hline efficiency & 0.69 & 0.46 & 0.67 & 0.85 & $-0.18^{* * *}$ \\
\hline farming & 0.64 & 0.48 & 0.63 & 0.70 & -0.07 \\
\hline general & 0.62 & 0.49 & 0.61 & 0.70 & -0.10 \\
\hline information & 0.70 & 0.46 & 0.67 & 0.86 & $-0.18^{* * *}$ \\
\hline integrity & 0.71 & 0.46 & 0.69 & 0.83 & $-0.14^{* *}$ \\
\hline negotiation & 0.63 & 0.48 & 0.60 & 0.83 & $-0.23^{* * *}$ \\
\hline trust_factor & -0.04 & 1.03 & -0.09 & 0.30 & $-0.39^{* * *}$ \\
\hline trust_sum & 3.99 & 2.41 & 3.87 & 4.77 & $-0.91^{* * *}$ \\
\hline \multicolumn{6}{|l|}{ additional covariates } \\
\hline $\operatorname{age}^{a}$ & 55.46 & 9.85 & 56.16 & 51.03 & $5.13^{* * *}$ \\
\hline bicycles & 0.15 & 0.49 & 0.14 & 0.21 & -0.07 \\
\hline distance to market & 12.90 & 52.43 & 13.55 & 8.64 & 4.91 \\
\hline distance to storage $\mathrm{e}^{b}$ & 14.32 & 24.24 & 14.22 & 15.00 & -0.78 \\
\hline groundnut & 0.47 & 0.50 & 0.42 & 0.82 & $-0.40^{* * *}$ \\
\hline hectares $^{b}$ & 4.27 & 5.27 & 3.85 & 6.88 & $-3.02^{* * *}$ \\
\hline heterogeneity & 0.35 & 0.48 & 0.31 & 0.58 & $-0.27^{* * *}$ \\
\hline household size $\mathrm{e}^{b}$ & 12.97 & 7.02 & 12.96 & 13.06 & -0.10 \\
\hline literate $^{b}$ & 0.44 & 0.50 & 0.40 & 0.69 & $-0.28^{* * *}$ \\
\hline male & 0.49 & 0.50 & 0.50 & 0.46 & 0.03 \\
\hline member & 0.75 & 0.43 & 0.77 & 0.62 & $0.15^{* * *}$ \\
\hline members' initiative & 0.31 & 0.24 & 0.31 & 0.32 & -0.02 \\
\hline motorcycles & 0.16 & 0.45 & 0.14 & 0.28 & $-0.14^{* *}$ \\
\hline onion & 0.42 & 0.49 & 0.47 & 0.07 & $0.40^{* * *}$ \\
\hline phone & 0.95 & 0.21 & 0.95 & 0.99 & -0.04 \\
\hline related to leader ${ }^{b}$ & 0.65 & 0.48 & 0.67 & 0.53 & $0.13^{* *}$ \\
\hline rice & 0.12 & 0.32 & 0.12 & 0.11 & 0.00 \\
\hline savings in bank & 0.12 & 0.32 & 0.10 & 0.24 & $-0.14^{* * *}$ \\
\hline savings in MFI & 0.36 & 0.48 & 0.32 & 0.56 & $-0.24^{* * *}$ \\
\hline $\operatorname{size}^{a}$ & 31.49 & 6.54 & 31.56 & 31.09 & 0.47 \\
\hline vehicles & 0.06 & 0.33 & 0.05 & 0.11 & -0.06 \\
\hline year of creation ${ }^{a}$ & 1997.14 & 10.49 & 1997.32 & 1995.99 & 1.34 \\
\hline year joined ${ }^{b}$ & 1999.79 & 8.90 & 2000.23 & 1997.06 & $3.16^{* * *}$ \\
\hline \multicolumn{6}{|c|}{$\begin{array}{l}\text { Notes: Information on collective commercialization in the } 2010 / 2011 \text { season is only available for } 538 \text { of } 798 \text { farmers } \\
\text { belonging to } 69 \text { out of } 73 \text { RPOs. We report averages and standard deviations for a sample of those } 538 \text { farmers, averages } \\
\text { in the subsamples of farmers that did and did not engage in collective commercialization in the } 2010 / 2011 \text { season and } \\
\text { results of two-sample } t \text { tests with the null of equal means among farmers not having engaged and having engaged in } \\
\text { collective commercialization. } \\
{ }^{a} \text { Information on these variables is only available for } 493 \text { out of } 538 \text { farmers of which } 426 \text { did not engage in collective } \\
\text { commercialization in the } 2010 / 2011 \text { season and } 67 \text { did. } \\
{ }^{b} \text { Information on these variables is only available for } 468 \text { out of } 538 \text { farmers of which } 404 \text { did not engage in collective } \\
\text { commercialization in the } 2010 / 2011 \text { season and } 64 \text { did. } \\
{ }^{*} p<0.10,{ }^{* *} p<0.05,{ }^{* *} p<0.01\end{array}$} \\
\hline
\end{tabular}




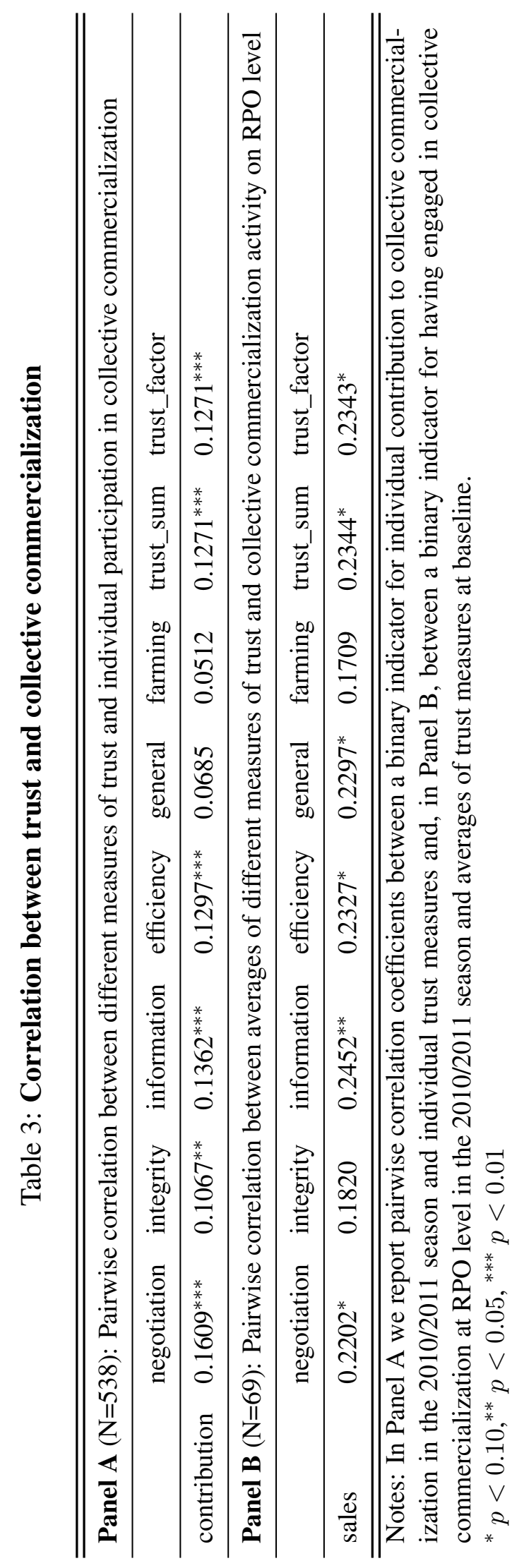


Overall, results from this section support the idea that trust in leaders and in members may play a significant role in fostering collective commercialization. Aiming at enhancing trust within RPOs to encourage collective commercialization, we organized a three-day training and discussion around the potential benefits and difficulties of coordinating towards collective commercialization in partnership with GRET and PINORD.

\section{Intervention}

We investigate issues of intra-group coordination and trust using a sample of Senegalese village-level RPOs for which we conducted a baseline survey in November and December 2011. At that time people may have assumed that there would be subsequent activities following the survey, but no details on the intervention were given. On the contrary, it was intentionally left unclear that there would be an intervention for some interviewees in the future. The sample for which the baseline survey was conducted was drawn from a dataset of 204 RPOs from 9 federations belonging to FONGS collected in 2009 from which we selected all organizations that stated collective commercialization as one of their main purposes. 73 RPOs belonging to 7 federations satisfied this criterion. Figure 1 shows the location of the sampled RPOs.

We randomly assigned an invitation to the training intervention to those 73 RPOs as follows:

- 23 RPOs served as pure control group, they were not invited to participate in the training intervention

- 50 RPOs received an invitation to participate in the training intervention

- in 12 RPOs, between one and four leaders but no members were invited to the training

- in 15 RPOs, between one and four members but no leaders were invited to the training

- in 23 RPOs, between one and four members and between one and four leaders were invited to the training

In each of the treated RPOs, at least two persons received an invitation. Invitees were randomly selected from lists of members and leaders obtained from the 


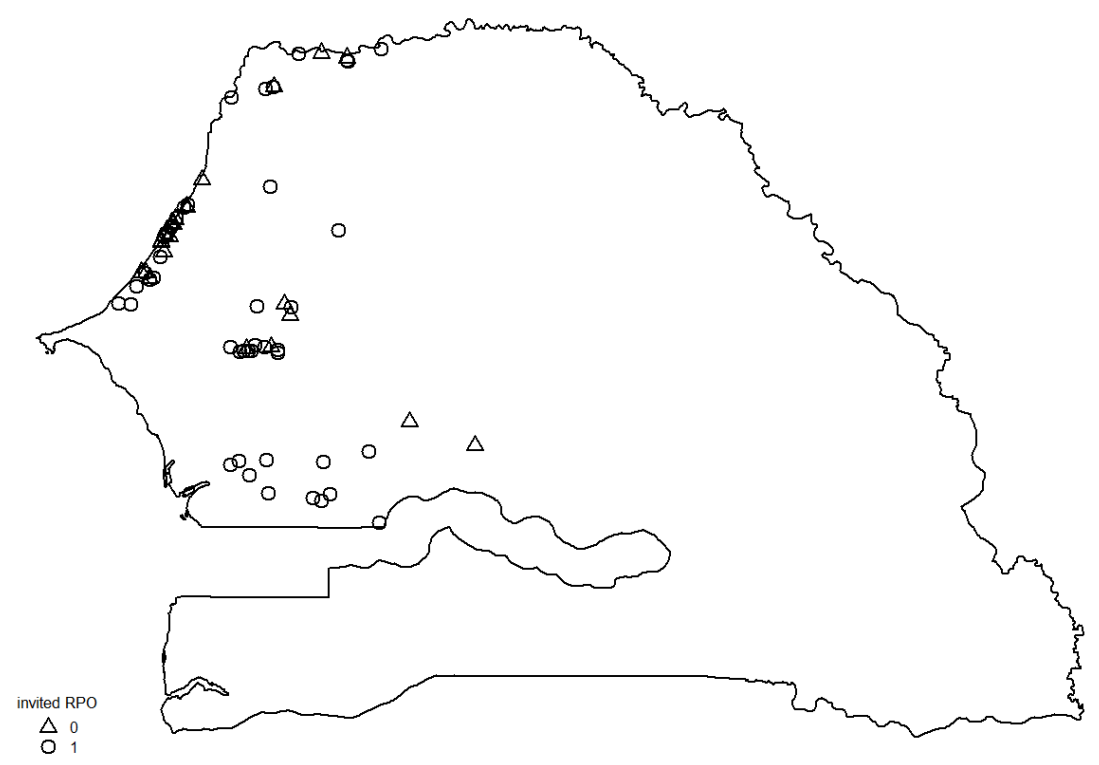

Figure 1: Location of sample RPOs in Senegal.

Map file downloaded from http://www.mapmakerdata.co.uk. s3-website-eu-west-1.amazonaws.com/library/stacks/ Africa/Senegal/index.htm, retrieved on 6 March 2015.

2009 survey. In all treated RPOs, a general assembly was convened shortly after the training to discuss its content with non-participants. To be able to consider both direct as well as spillover effects, we interviewed both invitees as well as non-invited individuals. In each RPO, 10 non-invited individuals were randomly selected for interviewing purposes.

The treatment and interview assignments were not fully respected in all RPOs. In some RPOs, more than four members (leaders) were invited. There were also instances where some invitees did not participate in the training, where more than the intended number of individuals participated in the training, or where the distribution of members and leaders was not fully respected. Moreover, the number of actually interviewed individuals (including invitees) ranges from 4 to 16 per RPO instead of the targeted 10 to 18 . Furthermore, due to missing information on outcome variables, we have to drop 8 individuals belonging to 7 RPOs from our sample. All in all, we work with a sample of 798 interviewed individuals consisting of 150 invitees, 447 non-invited individuals from treated 
RPOs, and 201 individuals from control RPOs 15

The intervention consisted of a three-day training conducted in January 2012. During the training, all participants were treated the same, i.e., members were not treated differently from leaders. The purpose of the training was to create awareness of the (potential) advantage of working together towards commercialization of agricultural produce and highlight particular group dynamics that are conducive to collective action. In terms of content, role plays, simple games and group exercises were to demonstrate the advantages of working together in terms of the benefits that can be generated and the costs that can be saved. Particular focus was put on sharing information and increasing transparency. Participants were encouraged to communicate the message they took away from the training to non-trained fellow farmers from their RPO upon return. One part of the training was to put together a plan for how these messages can be communicated and discussed with other group members.

The training sessions were organized in three modules, one for each day: (1) the potential and pitfalls of collective commercialization, (2) coordination within organizations - the role of communication in collective commercialization, and (3) motivation for coordination-members and leaders. ${ }^{16}$ An endline survey was conducted 2 to 4 weeks after the training.

In this paper we focus on estimating immediate effects of the intervention on intra-group relations. We do not capture long-term effects which would also have been interesting considering that trust may need time to grow. We cannot fully preclude a courtesy bias, i.e., that the respondents give the socially desirable answer when reporting higher trust levels after the intervention. However, baseline and endline data were collected via independent interviewers. They were not perceived as being related to GRET and PINORD, the organizations implementing the training, and were ignorant of the treatment status of RPOs as well as individuals. This separation of implementation and data collection should minimize the risk of a courtesy bias. If we found a spillover effect on trust of non-invited individuals in treated RPOs, we would be even less concerned about a courtesy bias. Indeed, our findings suggest that the intervention had an impact on trust of non-invited individuals (see Section 6), thus mitigating concerns related to such

\footnotetext{
${ }^{15}$ See Appendix B.1 for more details on the one-sided noncompliance. The distribution of RPOs and farmers by intended and actual treatment status as shown in Tables B.1 and B.2 in Appendix B.1 underline that treatment assignment is balanced which we further assess in Table 4

${ }^{16}$ The complete training manual is available from the authors upon request.
} 
bias.

Table 4: Balancing tests at RPO level

\begin{tabular}{|c|c|c|c|c|c|}
\hline Variable & $\begin{array}{l}\text { Mean } \\
(\mathrm{N}=73)\end{array}$ & $\begin{array}{l}\text { Standard } \\
\text { deviation }\end{array}$ & $\begin{array}{l}\text { Mean in } \\
\text { control group } \\
(\mathrm{N}=23)\end{array}$ & $\begin{array}{l}\text { Mean in } \\
\text { treatment group } \\
(\mathrm{N}=50)\end{array}$ & Difference \\
\hline \multicolumn{6}{|l|}{ trust outcomes } \\
\hline efficiency & 0.70 & 0.23 & 0.69 & 0.70 & -0.02 \\
\hline farming & 0.64 & 0.21 & 0.62 & 0.65 & -0.03 \\
\hline general & 0.63 & 0.23 & 0.62 & 0.64 & -0.02 \\
\hline information & 0.70 & 0.20 & 0.73 & 0.69 & 0.04 \\
\hline integrity & 0.71 & 0.22 & 0.72 & 0.71 & 0.01 \\
\hline negotiation & 0.63 & 0.20 & 0.61 & 0.64 & -0.03 \\
\hline trust_factor & -0.03 & 0.50 & -0.04 & -0.02 & -0.02 \\
\hline trust_sum & 4.01 & 1.17 & 3.98 & 4.03 & -0.04 \\
\hline \multicolumn{6}{|l|}{ additional covariates } \\
\hline $\operatorname{age}^{a}$ & 55.65 & 10.18 & 53.78 & 56.60 & -2.82 \\
\hline bicycles & 0.21 & 0.34 & 0.15 & 0.24 & -0.09 \\
\hline collective_sales ${ }^{b}$ & 0.29 & 0.46 & 0.18 & 0.34 & -0.16 \\
\hline distance to market & 10.16 & 28.91 & 5.59 & 12.26 & -6.67 \\
\hline distance to storage $e^{c}$ & 12.88 & 20.45 & 5.62 & 16.51 & $-10.89^{* *}$ \\
\hline groundnut & 0.38 & 0.49 & 0.26 & 0.44 & -0.18 \\
\hline hectares ${ }^{c}$ & 3.84 & 4.34 & 2.64 & 4.43 & -1.79 \\
\hline heterogeneity & 0.36 & 0.48 & 0.30 & 0.38 & -0.08 \\
\hline household size ${ }^{c}$ & 12.70 & 4.01 & 11.61 & 13.25 & -1.64 \\
\hline literate $^{c}$ & 0.43 & 0.31 & 0.46 & 0.41 & 0.05 \\
\hline male & 0.41 & 0.29 & 0.41 & 0.42 & -0.01 \\
\hline member & 0.79 & 0.15 & 0.81 & 0.78 & 0.03 \\
\hline members' initiative & 0.62 & 0.49 & 0.52 & 0.66 & -0.14 \\
\hline motorcycles & 0.18 & 0.30 & 0.14 & 0.20 & -0.07 \\
\hline onion & 0.47 & 0.50 & 0.57 & 0.42 & 0.15 \\
\hline phone & 0.95 & 0.07 & 0.94 & 0.95 & -0.01 \\
\hline related to leader ${ }^{c}$ & 0.63 & 0.35 & 0.73 & 0.58 & 0.15 \\
\hline rice & 0.15 & 0.36 & 0.17 & 0.14 & 0.03 \\
\hline savings in bank & 0.14 & 0.16 & 0.13 & 0.15 & -0.02 \\
\hline savings in MFI & 0.33 & 0.19 & 0.30 & 0.35 & -0.05 \\
\hline $\operatorname{size}^{a}$ & 31.38 & 8.37 & 31.48 & 31.33 & 0.14 \\
\hline vehicles & 0.11 & 0.21 & 0.13 & 0.10 & 0.04 \\
\hline year of creation ${ }^{a}$ & 1996.69 & 10.08 & 1994.96 & 1997.58 & -2.62 \\
\hline year joined ${ }^{c}$ & 1999.48 & 7.40 & 1998.87 & 1999.78 & -0.90 \\
\hline
\end{tabular}

Notes: We report averages and standard deviations for the full sample of 73 RPOs, averages in the subsamples of RPOs in treatment and control group and results of two-sample t tests with the null of equal means in control and treatment group at baseline.

${ }^{a}$ Information on these variables is only available for 68 out of 73 RPOs of which 45 belong to the treatment group and 23 to the control group.

${ }^{b}$ Information on this variable is only available for 69 out of 73 RPOs of which 47 belong to the treatment group and 22 to the control group.

${ }^{c}$ Information on these variables is only available for 66 out of 73 RPOs of which 44 belong to the treatment group and 22 to the control group.

${ }^{*} p<0.10,{ }^{* *} p<0.05,{ }^{* * *} p<0.01$

To ensure that the assignment of the treatment is independent of any baseline characteristics, we run a series of balancing tests relating RPO's invitations to participate in the training to individual and RPO-level characteristics. In Table 4 we report means of individual and RPO-level characteristics in invited and noninvited RPOs at baseline as well as results from two-sample t tests with the null of equal means in invited and non-invited RPOs. Results suggest that the treatment 
allocation is fully independent of average baseline trust levels,.$^{17}$ and a range of further covariates. Treatment and control group only differ significantly with respect to the average walking distance of the farmers to the RPO's storage site. 18 Multivariate tests for equality of means of baseline trust in invited and non-invited groups reveal no significant differences between treatment and control groups. 19 Within invited RPOs, we find no significant differences in average baseline trust when comparing invitees and non-invitees (see Table 5 for details on binary trust measures and Table B.4 in Appendix B.2 for details on ordinal trust measures).

\footnotetext{
${ }^{17}$ See Table B.3 in Appendix B.2 for balancing tests using ordinal trust measures.

${ }^{18}$ Information on this variable is only available for 66 out of 73 RPOs.

${ }^{19}$ Wilks' lambda statistic 0.8651 , Pillai's trace statistic 0.1349 , Lawley-Hotelling trace statistic and Roy's largest root statistic 0.1560 , p-value 0.1311 .
} 
Table 5: Changes in trust by intended treatment status at individual level

\begin{tabular}{|c|c|c|c|c|c|}
\hline Trust outcomes & Sample & $\mathrm{N}$ & Baseline (BL) & Endline (EL) & Diff. BL EL P-value \\
\hline \multirow[t]{5}{*}{ negotiation } & A. Invitees & 150 & 0.68 & 0.77 & 0.0940 \\
\hline & B. Non-Invitees in $\mathrm{T}$ & 447 & 0.63 & 0.75 & 0.0001 \\
\hline & C. Non-Invitees in C & 201 & 0.61 & 0.62 & 0.8379 \\
\hline & Diff. A B P-value & & 0.2999 & 0.7531 & \\
\hline & Diff. B C P-value & & 0.6070 & 0.0006 & \\
\hline \multirow[t]{5}{*}{ integrity } & A. Invitees & 150 & 0.74 & 0.79 & 0.3433 \\
\hline & B. Non-Invitees in $\mathrm{T}$ & 447 & 0.69 & 0.69 & 0.9423 \\
\hline & C. Non-Invitees in C & 201 & 0.71 & 0.59 & 0.0089 \\
\hline & Diff. A B P-value & & 0.2807 & 0.0251 & \\
\hline & Diff. B C P-value & & 0.6459 & 0.0096 & \\
\hline \multirow[t]{5}{*}{ information } & A. Invitees & 150 & 0.71 & 0.82 & 0.0209 \\
\hline & B. Non-Invitees in $\mathrm{T}$ & 447 & 0.68 & 0.74 & 0.0325 \\
\hline & C. Non-Invitees in C & 201 & 0.72 & 0.68 & 0.3290 \\
\hline & Diff. A B P-value & & 0.5117 & 0.0546 & \\
\hline & Diff. B C P-value & & 0.2677 & 0.0824 & \\
\hline \multirow[t]{5}{*}{ efficiency } & A. Invitees & 150 & 0.75 & 0.83 & 0.0657 \\
\hline & B. Non-Invitees in T & 447 & 0.68 & 0.70 & 0.6131 \\
\hline & C. Non-Invitees in $\mathrm{C}$ & 201 & 0.68 & 0.64 & 0.3448 \\
\hline & Diff. A B P-value & & 0.1378 & 0.0012 & \\
\hline & Diff. B C P-value & & 0.9852 & 0.1232 & \\
\hline \multirow[t]{5}{*}{ general } & A. Invitees & 150 & 0.64 & 0.78 & 0.0074 \\
\hline & B. Non-Invitees in $\mathrm{T}$ & 447 & 0.62 & 0.65 & 0.4043 \\
\hline & C. Non-Invitees in C & 201 & 0.61 & 0.54 & 0.1906 \\
\hline & Diff. A B P-value & & 0.7289 & 0.0032 & \\
\hline & Diff. B C P-value & & 0.6773 & 0.0084 & \\
\hline \multirow[t]{5}{*}{ farming } & A. Invitees & 150 & 0.66 & 0.78 & 0.0206 \\
\hline & B. Non-Invitees in $\mathrm{T}$ & 447 & 0.64 & 0.67 & 0.2913 \\
\hline & C. Non-Invitees in C & 201 & 0.61 & 0.56 & 0.3123 \\
\hline & Diff. A B P-value & & 0.6556 & 0.0136 & \\
\hline & Diff. B C P-value & & 0.4970 & 0.0064 & \\
\hline \multirow[t]{5}{*}{ trust_sum } & A. Invitees & 150 & 4.17 & 4.77 & 0.0162 \\
\hline & B. Non-Invitees in $\mathrm{T}$ & 447 & 3.95 & 4.21 & 0.1062 \\
\hline & C. Non-Invitees in C & 201 & 3.95 & 3.63 & 0.1730 \\
\hline & Diff. A B P-value & & 0.3311 & 0.0087 & \\
\hline & Diff. B C P-value & & 0.9785 & 0.0036 & \\
\hline \multirow[t]{5}{*}{ trust_factor } & A. Invitees & 150 & 0.04 & 0.29 & 0.0168 \\
\hline & B. Non-Invitees in $\mathrm{T}$ & 447 & -0.05 & 0.05 & 0.1178 \\
\hline & C. Non-Invitees in $\mathrm{C}$ & 201 & -0.05 & -0.19 & 0.1652 \\
\hline & Diff. A B P-value & & 0.3266 & 0.0080 & \\
\hline & Diff. B C P-value & & 0.9994 & 0.0041 & \\
\hline
\end{tabular}

Notes: We report averages of different trust measures in subsamples of invitees, non-invitees in the treatment group (Ttreatment group), non-invitees in the control group ( $\mathrm{C}$ - control group) at baseline (BL-baseline) and endline (ELendline) as well as p-values of two-sample t tests with the null of equal means. 


\section{Experimental design}

\subsection{Hypotheses}

Ostrom and Ahn (2003) provide a theoretical framework for analyzing issues of collective action which can be applied to analyzing collective commercialization as an example of collective action. Success and failure of collective action is determined by a complex configuration of various factors which they categorize as forms of social capital. They argue that the different forms of social capitaltrustworthiness, networks and institutions-enhance trust which they see as the core link between social capital and collective action. Figure 2 shows the relationships between the forms of social capital, trust, and collective action.

\section{Forms of Social Capital}

Trustworthiness $\quad$ Contextual Variables

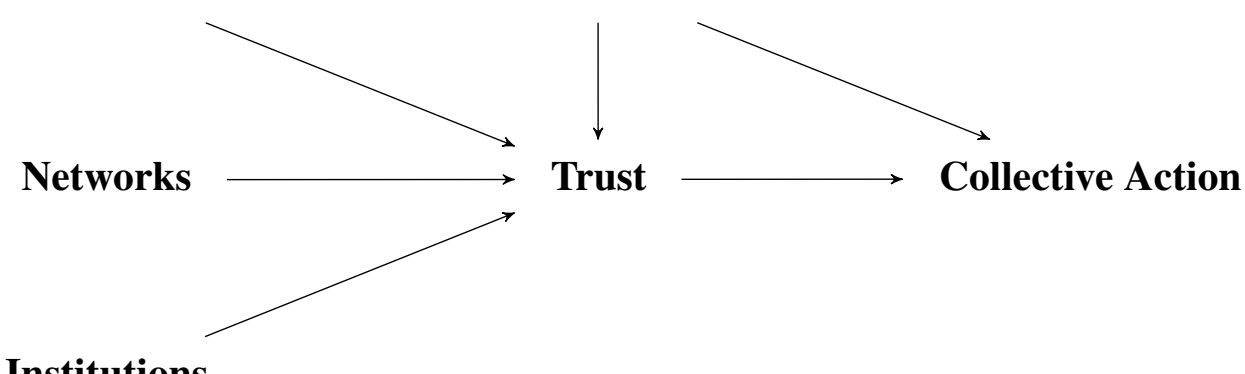

Figure 2: Social capital, trust, and collective action.

(Ostrom and Ahn, 2003, p. xvii)

Trust reduces opportunistic behavior and, thus, transaction costs (Collier, 2002 Putnam, 1993). Applied to the context of collective commercialization in RPOs, farmers who are organized in RPOs need to be trustworthy and sufficiently connected with each other, and the RPO needs to provide adequate institutions for trust to be prevalent within the RPO and for collective commercialization to be successful. Trust in leaders allows the trusting farmer to commit to commercialization despite the risk of loss if the leaders do not behave as the trusting farmer expected. Trust in members allows the trusting farmer to commit to commercialization despite the risk of loss if the fellow farmers do not participate in the joint endeavors as expected by the trusting farmer.

If the training intervention increases the different forms of social capital, it 
will enhance trust and ultimately lead to more successful collective commercialization and potentially other collective endeavors in treated RPOs. Putnam (1993) distinguishes between horizontal networks bringing together individuals of equivalent status, e.g. fellow members or fellow leaders, and vertical networks bringing together individuals from different hierarchical levels, e.g. members and leaders. Dense horizontal networks with the capability of efficiently transmitting information across individuals create incentives to behave in a trustworthy manner. Repeated interactions among individuals are seen as a sign of robust networks (Ostrom and Ahn, 2003). We expect that the training intervention strengthens existing horizontal and vertical networks and may even create new ones through repeated interactions of farmers. Put differently, we expect the intervention to have a positive effect on participating leaders' trust in other leaders and on participating members' trust in other members through tightening existing bonds and creating new ones during and after the joint field trip to the training. Similarly, in RPOs where both members and leaders participate, the training may increase trust between leaders and members through strengthening and/or creating vertical networks. We hypothesize that such increases in social capital will materialize in a positive treatment effect on trust in members and on trust in leaders.

Both networks and institutions change the incentive structure of individuals with institutions creating incentives for both the trusting and the trusted party to behave in a trustworthy manner (Ostrom and Ahn, 2003). We expect that the intervention clarifies the process of collective commercialization as one form of collective action and the rules involved and, thus, creates a common understanding of the relevant institutions. In other words, trained members (leaders) may obtain a better understanding of leaders' (members') role and position which may increase members' (leaders') trust in leaders (members) even if no leaders (members) are present during the training. Further, the intervention may also create positive spillover effects, i.e., increase non-participants' trust in leaders and members. Participants may convey their newly acquired understanding of leaders' and members' role and position to non-participants during the general assembly held shortly after the training. We hypothesize that such increases in social capital will again materialize in a positive treatment effect on trust in members and on trust in leaders. 


\subsection{Measures of trust}

We consider six survey measures of trust capturing different aspects of trust within a RPO that we consider to be important for successful collective commercialization. We distinguish between trust in leaders and trust in members.

Measuring general trust ${ }^{20}$ in unknown others based on the standard trust question used in the General Society Survey (GSS) ${ }^{21}$ or the World Values Survey ${ }^{22}$ has been challenged on the grounds that it is unclear what this question actually measures (Beugelsdijk, 2006; Durlauf, 2002; Sobel, 2002; Yamagishi et al., 1999). Results from relating general trust in strangers as stated in the survey question to behavior in experimental trust games are mixed ${ }^{23}$

However, survey measures are commonly used for studying trust as a collective property of organizations, i.e., for studying trust in known others. In the management literature, the perception of the characteristics of significant others within the working context is looked at for studying trust between and within organizational levels (Tschannen-Moran and Hoy, 2000). We borrow from this literature to asses how characteristics of members and leaders are perceived within the RPO context. ${ }^{24}$ For trust in leaders, we distinguish between trust in their motives and trust in their competence with regard to collective commercialization. Trust in leaders' motives refers to a farmer's beliefs that the leaders are otherregarding or not, i.e., that the leaders have motives to perform an action beneficial to others or not. Trust in leaders' competence refers to a farmer's beliefs that the leaders have credible expertise (Buck and Alwang, 2011; Twyman et al., 2008).

\footnotetext{
${ }^{20}$ General trust is a baseline expectation of others' trustworthiness (Yamagishi, 2001).

21 “Generally speaking, would you say that most people can be trusted or that you can't be too careful in dealing with people?"- "Most people can be trusted." or "Can't be too careful."

22 "Generally speaking, would you say that most people can be trusted or that you need to be very careful in dealing with people?"- "Most people can be trusted." or "Need to be very careful."

${ }^{23}$ Glaeser et al. (2000) find in a sample of students at Harvard University that trust as stated in the survey has no predictive power for trust elicited from the trust game, but for trustworthiness. For a representative sample of the German population, Fehr et al. (2002) find a relation of trust as measured in the survey and experimental trust, but not for trustworthiness. Sapienza et al. (2007) find that trust as stated in the survey predicts experimental trust for a sample of MBA students at the University of Chicago. For a heterogeneous Dutch sample, Bellemare and Kröger (2007) find no significant link between trust as measured in the survey to neither experimental trust nor trustworthiness. Naef and Schupp (2009) have developed a new survey measure for trust in strangers that is more precise that the GSS question and have used it in the German SocioEconomic Panel showing that survey and experimental measures of trust are connected in the sense that the trust game measures trust in strangers.

${ }^{24}$ See Kramer (1999) and Möllering et al. (2004) for reviews of the conceptualization of trust in organizational theory and the benefits of and conditions for trust in organizational systems. See Seppänen et al. (2007) for a review of the empirical research of inter-organizational trust.
} 
We consider four aspects of trust in leaders asking respondents to which extent they agree with the following statements:

(1) “The RPO's board is capable of negotiating better prices for our produce than I am capable of myself."

(2) "Board members defend the RPO's interests and their own interests in equal measure."

(3) "If the RPO's board says that I can achieve better prices if I wait a little, they do so because they have adequate information."

(4) "If I invest my money or my produce in the RPO, it will be used efficiently."

For trust in members, we consider both general trust and trust specific to the farming context asking respondents to which extent they agree with the following statements:

(5) "The majority of people in my RPO are trustworthy."

(6) "I can trust the people from the RPO to look after my field during an absence of two months."

Originally, all trust measures are recorded on a four-point Likert-type scale. The items to choose from are (1) "Do not agree at all", (2) "Do not really agree", (3) "Agree", and (4) "Fully agree". However, given that the average trust levels at baseline are well above 3 for all measures of trust (see Table B.4 in Appendix B.2), we use binary variables as regressands in the empirical analysis which are equal to one if respondents fully agree with one of the above statements.

Hence, for trust in leaders, we create a binary variable negotiation equal to one if the respondent fully agrees with the first statement, a binary variable integrity equal to one if the respondent fully agrees with the second statement, a binary variable information equal to one if the respondent fully agrees with the third statement, and a binary variable efficiency equal to one if the respondent fully agrees with the fourth statement. For trust in members, we create a binary variable general equal to one if the respondent fully agrees with the fifth statement, and a binary variable farming equal to one if the respondent fully agrees with the sixth statement.

Moreover, we create two comprehensive indices of trust. For trust_sum we take the sum over the six binary trust measures such that values of trust_sum 
range from 0 to 6.25 For trust_factor we run a factor analysis with the six binary trust measures. Values of the resulting index of trust range from -1.74 to 0.812

\section{Treatment effects at RPO level}

In this section we present our empirical strategy and regression results for the causal treatment effects of the (invitation to the) training on average trust.

Table 6: Changes in trust by intended treatment status at RPO level

\begin{tabular}{|c|c|c|c|c|c|}
\hline Trust outcomes & Sample & $\mathrm{N}$ & Baseline (BL) & Endline (EL) & Diff. BL EL P-value \\
\hline \multirow[t]{3}{*}{ negotiation } & Control (C) & 23 & 0.61 & 0.63 & 0.8413 \\
\hline & Treatment $(\mathrm{T})$ & 50 & 0.64 & 0.76 & 0.0029 \\
\hline & Diff. C T P-value & & 0.5877 & 0.0113 & \\
\hline \multirow[t]{3}{*}{ integrity } & Control (C) & 23 & 0.72 & 0.60 & 0.1156 \\
\hline & Treatment $(\mathrm{T})$ & 50 & 0.71 & 0.72 & 0.7788 \\
\hline & Diff. C T P-value & & 0.8566 & 0.0783 & \\
\hline \multirow[t]{3}{*}{ information } & Control (C) & 23 & 0.73 & 0.69 & 0.5575 \\
\hline & Treatment $(\mathrm{T})$ & 50 & 0.69 & 0.77 & 0.0670 \\
\hline & Diff. C T P-value & & 0.3965 & 0.2044 & \\
\hline \multirow[t]{3}{*}{ efficiency } & Control (C) & 23 & 0.69 & 0.66 & 0.6719 \\
\hline & Treatment $(\mathrm{T})$ & 50 & 0.70 & 0.73 & 0.5387 \\
\hline & Diff. C T P-value & & 0.7572 & 0.2345 & \\
\hline \multirow[t]{3}{*}{ general } & Control (C) & 23 & 0.62 & 0.56 & 0.4360 \\
\hline & Treatment $(\mathrm{T})$ & 50 & 0.64 & 0.69 & 0.3513 \\
\hline & Diff. C T P-value & & 0.7215 & 0.0708 & \\
\hline \multirow[t]{3}{*}{ farming } & Control (C) & 23 & 0.62 & 0.57 & 0.5411 \\
\hline & Treatment $(\mathrm{T})$ & 50 & 0.65 & 0.70 & 0.2368 \\
\hline & Diff. C T P-value & & 0.5602 & 0.0558 & \\
\hline \multirow[t]{3}{*}{ trust_sum } & Control (C) & 23 & 3.98 & 3.71 & 0.4762 \\
\hline & Treatment $(\mathrm{T})$ & 50 & 4.03 & 4.38 & 0.1843 \\
\hline & Diff. C T P-value & & 0.8838 & 0.0657 & \\
\hline \multirow[t]{3}{*}{ trust_factor } & Control (C) & 23 & -0.04 & -0.15 & 0.4682 \\
\hline & Treatment $(\mathrm{T})$ & 50 & -0.02 & 0.12 & 0.1944 \\
\hline & Diff. C T P-value & & 0.8976 & 0.0691 & \\
\hline
\end{tabular}

Notes: We report averages of different trust measures in treatment group (T-treatment group) and control group (Ccontrol group) at baseline (BL_baseline) and endline (EL_endline) as well as p-values of two-sample t tests with the null of equal means.

Descriptive evidence suggests a positive impact of the training intervention on intra-RPO trust. Table 6 reports two-sample $t$ tests with the null of equal means in baseline and endline for treatment and control group. Moreover, we report two-sample $t$ tests with the null of equal means for treatment and control group in both baseline and endline. Treatment RPOs report higher levels of average trust

\footnotetext{
${ }^{25}$ trust_sum has a mean of 4.08 and a standard deviation of 2.35 .

${ }^{26}$ trust_factor has a mean of 0 and a standard deviation of 1.
} 
at endline compared to baseline for all measures of trust. We observe statistically significant differences between average trust in leaders' negotiation skills and their informational advantages. While we find no significant differences between average trust in treatment and control group at baseline, treatment RPOs report significantly higher levels of trust at endline compared to control RPOs for trust in leaders' negotiation skills and their integrity, for general and farming-specific trust in members, and for both comprehensive trust indices. ${ }^{27}$

\subsection{Empirical strategy}

To further study the intervention's impact on trust, we estimate treatment effects on RPO level. To account for the one-sided noncompliance ${ }^{28}$ that may be related to individual and RPO-level characteristics, we first present estimations of the intention-to-treat effect, i.e., the treatment effect of the invitation to participate in the training intervention. We draw on the random assignment of the invitations (and the time dimension of our data) to identify the causal effect of such an invitation at the RPO level on our different measures of trust.

In our main regressions we will allow for fixed effects to pick up differences in unobservable characteristics between individuals and/or RPOs. Although treatment was randomly assigned, the relatively small number of RPOs may entail some small sample imbalances in observed and/or unobserved characteristics. To be on the safe side, we include fixed effects. Since our analysis is based on two time periods, fixed effects regressions are identical to taking first differences in a regression with no further covariates. ${ }^{29}$ Thus, we estimate:

$$
\Delta \text { trust }_{g}=\gamma_{0}+\gamma_{1} R P O \_ \text {invitation }{ }_{g}+\nu_{g}
$$

where $\Delta$ trust $_{g}=$ trust $_{g, t=1}-$ trust $_{g, t=0}$ is the difference between average trust

\footnotetext{
${ }^{27}$ For descriptive evidence on the intervention's impact on ordinal trust measures see Table B.4 in Appendix B.2.

${ }^{28}$ Participation in the training intervention was voluntary among those who were invited, but no one from the control RPOs had access to the training intervention. For details on the one-sided noncompliance see Appendix B.1.

${ }^{29}$ Double differencing not only removes biases in an endline comparison between the treatment and control group resulting from permanent differences, but also biases from a comparison over time in the treatment group resulting from time trends that are unrelated to the intervention. The key identifying assumption (common trend assumption) for the estimation of a causal treatment effect is that trends in development of trust would on average be the same in treatment and control groups in the absence of the training intervention (Imbens and Wooldridge, 2009).
} 
in RPO $g$ at endline $t=1$ and baseline $t=0$ and RPO_invitation $g$ is a binary variable equal to one if at least one member or leader of RPO $g$ has received an invitation to participate in the training intervention. $\nu_{g}$ is a random disturbance term for RPO $g$. Given the random assignment of the invitations, the estimated coefficient $\widehat{\gamma}_{1}$ is our main coefficient of interest, the causal effect of the invitation to the training on average trust. It captures both the treatment effect for those individuals who have personally been invited (direct treatment effect) and those who have only been interviewed (spillover effect) which we will disentangle in Section 6

For illustrative purposes, we also report results of level regressions, i.e., of regressions without fixed effects. Using endline data, we estimate the following linear model:

$$
\text { trust }_{g, t=1}=\beta_{0}+\beta_{1} R P O \_ \text {invitation }_{g}+\varepsilon_{g}
$$

where trust $_{g, t=1}$ is a measure of average trust in RPO $g$ at endline $t=1$ and $R P O \_$invitation $g$ is defined as above. Hence, $\widehat{\beta}_{1}$ is our main coefficient of interest in this model, the average causal effect of the invitation to the training on average trust. $\varepsilon_{g}$ is a random disturbance term for RPO $g$.

To address concerns with regard to statistical inference in the small crosssection sample of 73 RPOs, we provide both OLS standard errors and classical inference as well as randomization inference. For the intention-to-treat estimations based on equations (1) and (2), we implement permutation tests which do not rely on asymptotic approximation and whose properties are hence independent of sample size ${ }^{30}$ Randomization inference is based on the sharp null hypothesis of no treatment effect for anybody and provides exact finite sample inference. We conduct randomization inference by forming 9000 randomly drawn permutations of the randomization vector for the 73 RPOs and calculating the regression estimates using regressions as presented in equations (1) and (2). For each outcome of interest, this provides the finite sample distribution of the estimated treatment effect under the null of no effect, upon which we base our two-sided test of zero effect. For recent applications of this approach see for example Bloom et al.

\footnotetext{
${ }^{30}$ Randomization inference is typically only done for intention-to-treat estimations. Randomization inference in the instrumental variable regression context would required modeling assumptions since the compliance type is not known for all observations, i.e. the counterfactual value of RPO_training if RPO_invitation was changed.
} 
(2013) and Landmann and Frölich (2015).

In next step, we estimate the effect of treatment on the treated, i.e., the causal effect of the training intervention on those who participated, using the randomly assigned invitations as an instrumental variable for training received. We estimate:

$$
\begin{aligned}
& \text { trust }_{g, t=1}=\delta_{0}+\delta_{1} R P O \_ \text {training }_{g}+v_{g} \\
& \text { trust }_{g}=\eta_{0}+\eta_{1} R P O \_ \text {training } \\
&
\end{aligned}
$$

where RPO_training is a binary variable equal to one if at least one member or leader of RPO $g$ participated in the training which we instrument for by $R P O \_$invitation $_{g}$. The first stage regression coefficient is 0.88 . Since both the treatment variable and the instrument are binary, the instrumental variable regression is identical to the Wald (or LATE) estimator. The estimated effects are identical to those of equations (1) and (2) divided by 0.88 . We therefore report randomization inference only for the reduced form regressions, estimates only differ by this scaling factor. The $\mathrm{F}$ statistic from the first-stage regressions is 351.60, the adjusted $R^{2}$ is 0.6937. trust $_{g, t=1}$ and $\Delta$ trust $_{g}$ are defined as above. $v_{g}$ and $\omega_{g}$ are random disturbance terms for RPO $g$. Thus, the estimated coefficients $\widehat{\delta}_{1}$ and $\widehat{\eta}_{1}$ are our main coefficients of interest, the causal effects of the training on average trust in those RPOs who participated.

\subsection{Regression results}

In Table 7 we report estimated treatment effects on average trust. In panel A we report results from regressions using endline data while panel B shows results from first differences estimations. We present intention-to-treat effects based on reduced form regressions as specified in equations (1) and (2), and we present treatment on the treated effects based on instrumental variable regressions as specified in equations (3) and (4).

The regression results confirm the descriptive evidence presented above. An invitation to the training significantly increases both comprehensive trust measures. The estimated treatment effect becomes even larger when looking at the effect of the training itself on average trust. In detail, we find a significantly positive intention-to-treat effect of between 11 and 13 percentage points for average trust in leaders' negotiation skills, their integrity and their informational advan- 
tage ${ }^{31}$ We further find a significantly positive intention-to-treat effect of between 10 and 13 percentage points for both measures of trust in members. These positive treatment effects increase to 12 to 15 percentage points when considering the effect of the training itself.

We run several robustness checks to confirm these results. First, we enlarge the model in first differences by allowing for onion-specific and rice-specific time trends and by controlling for the number of invited/trained persons per RPO ${ }^{32}$ Qualitatively, results remain unchanged compared to the model in first differences without covariates. Second, we follow McKenzie (2012) who argues that large improvements in power can arise when estimating treatment effects via an Analysis of Covariance (ANCOVA) estimation compared to using the differencein-differences specification. We estimate the ANCOVA specifications without covariates, with controls for onion and rice cultivation and with a control for the number of invited/trained persons per RPO. Results are similar to those from the difference-in-differences estimations and robust to controlling for onion and rice cultivation and to controlling for the number of invitees/participants. For details on these robustness checks see Appendix B.3.

\footnotetext{
${ }^{31}$ Recall that baseline trust averages range between 0.63 for trust in leaders' negotiation skills and general trust in members and 0.71 for trust in leaders' integrity (see Table 4 )

${ }^{32}$ Note that when including covariates to the model in first differences, it is no longer equivalent to a fixed effects model.
} 


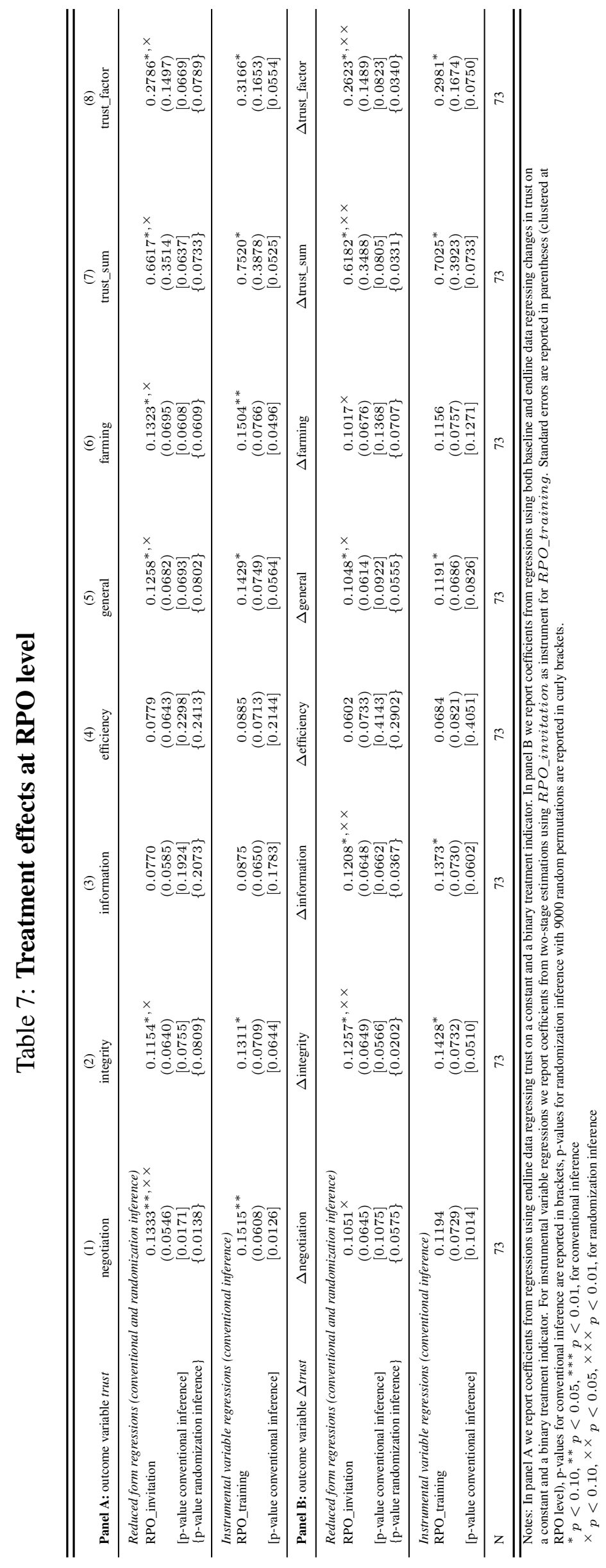




\section{Treatment effects at individual level}

In this section we present treatment effects of the (invitation to the) training on trust based on individual-level regressions permitting us to disentangle the effect of having personally been invited from a potential spillover effect on non-invited farmers within treated RPOs. We start by assessing descriptively whether trust has evolved between the baseline and endline survey and whether it has evolved differently in treatment and control groups. Table 5 reports two-sample t tests with the null of equal means in baseline and endline for invitees, non-invitees in invited RPOs and for non-invitees in non-invited RPOs. Moreover, we report twosample $t$ tests with the null of equal means for invitees and non-invitees in invited RPOs in both baseline and endline and for non-invitees in invited and non-invited RPOs in both baseline and endline. Invitees report higher levels of trust at endline compared to baseline for all measures for trust. This difference is statistically significant for all measures except for trust in leaders' integrity. Further indication of a positive direct treatment effect comes from the comparison of invitees with non-invitees from invited RPOs. While we observe no significant difference at baseline, we observe significant differences for all measures of trust in leaders but negotiation at endline. We also find descriptive evidence for a positive spillover effect within invited RPOs. Comparing non-invitees from invited and noninvited RPOs, we find no significant differences at baseline. At endline, however, non-invitees in invited RPOs report significantly higher trust levels for all trust measures but efficiency compared to non-invitees from non-invited RPOs.

\subsection{Empirical strategy}

To further study spillover effects and direct treatment effects, we estimate:

$$
\begin{aligned}
\text { trust }_{i g} & =\alpha_{0}+\alpha_{1} \text { spillover_invitation }_{i g}+\alpha_{2} \text { personal_invitation } \\
& +\tau_{i g}
\end{aligned}
$$

where $\Delta$ trust $_{i g}=$ trust $_{i g, t=1}-$ trust $_{i g, t=0}$ is the difference between trust of person $i$ in RPO $g$ at endline $t=1$ and baseline $t=0$, spillover_invitation ${ }_{i g}$ is a binary variable equal to one if some member or leader from RPO $g$ other than person $i$ has received an invitation, personal_invitation $i$ is a binary variable equal to one if person $i$ has received an invitation to participate in the training 
intervention, and $\tau_{i g}$ is a random disturbance term for individual $i$ in RPO $g$. Hence, the estimated coefficient $\widehat{\alpha_{1}}$ captures any potential spillover effects while $\widehat{\alpha_{2}}$ captures the effect of having personally been invited.

Again, we also estimate the causal effect of the training using an instrumental variable strategy. We estimate:

$$
\Delta \text { trust }_{i g}=\theta_{0}+\theta_{1} \text { spillover_training }_{i g}+\theta_{2} \text { personal_training } i+\kappa_{i g}
$$

where spillover_training $g_{i g}$ is a binary variable equal to one if some member or leader from RPO $g$ other than person $i$ has participated in the training and personal_training $i$ is a binary variable equal to one if person $i$ has participated in the training intervention. We instrument for spillover_training $g_{i g}$ and personal_training $_{i}$ using RPO_invitation and personal_invitation $_{i}{ }^{33}$ The F statistic from the first-stage regression of spillover_training $g_{i g}$ amounts to 174.18, the adjusted $R^{2}$ to 0.6062 . For personal_training $i$ the $\mathrm{F}$ statistic is 240.95 and the adjusted $R^{2}$ is 0.6403. $\kappa_{i g}$ is a random disturbance term for individual $i$ in RPO $g$, and $\Delta$ trust $_{i g}$ is defined as above. Hence, the estimated coefficient $\widehat{\theta_{1}}$ captures any potential spillover effects while $\widehat{\theta_{2}}$ captures the effect of having personally been trained.

To gain further insights into spillover effects, we also estimate regressions as specified in equation (6) separately for subsamples containing only members or only leaders. For the subsample of members, we further split the spillover effect by treatment type, i.e., by whether only members were treated, only leaders, or both. In these regressions, we instrument for spillover_training ${ }_{i g}$ and

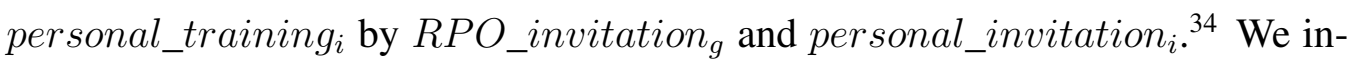
strument for spillover_training_OL $L_{i g}$, spillover_training_OM $M_{i g}$, spillover_ training_LM $M_{i g}$ and personal_training ${\text { using } R P O \_i n v i t a t i o n \_O L_{g}, R P O \_}$ invitation_OMg,$R P O \_i n v i t a t i o n \_L M_{g}$ and personal_invitation ${ }_{i}$. The highly significant correlation coefficients range between -0.2863 and 0.9021 .

\footnotetext{
${ }^{33}$ The highly significant correlation coefficients are 0.5702 for spillover_training and RPO_invitation, 0.2700 for personal_training and RPO_invitation, -0.3509 for personal_invitation and spillover_training and 0.7993 for personal_invitation and personal_training.

${ }^{34}$ The highly significant correlation coefficients are 0.6328 for spillover_training and RPO_invitation, 0.2190 for personal_training and RPO_invitation, -0.2940 for personal_invitation and spillover_training and 0.7813 for personal_invitation and personal_training.
} 


\subsection{Regression results}

In Table 8 we report estimated treatment effects on individual trust. We present intention-to-treat effects based on reduced form regressions as specified in equation (5), and results from instrumental variable estimations as specified in equation (6). Results hint at a significantly positive treatment effect of having personally received an invitation. In detail, we find a significant personal intentionto-treat effect of 13 to 20 percentage points for all individual trust measures but trust in leaders' negotiation skills. ${ }^{35}$ These effects increase to 15 to 24 percentage points when considering the treatment effect of the training.

To gain further insights into spillover effects and direct treatment effects, we rerun estimations as specified in equations (5) and (6) on subsamples containing only members or only leaders. Results are presented in Tables 9 (members) and 10 (leaders). In Table 9 we present intention-to-treat effects based on reduced form regressions on a subsample of members as specified in equation (5) and results from instrumental variable estimations on a subsample of members as specified in equation (6). For members we find both a significantly positive personal treatment effect as well as a significantly positive spillover effect. In particular, we find significantly positive direct treatment effects of 19 to 20 percentage points for trust in leaders' integrity and their informational advantage as well as a significant personal intention-to-treat effect of 18 percentage points on general trust and farming specific trust in members. For trust in leaders' negotiation skills, their integrity, and their informational advantages, results appear to be indicating a significantly positive spillover effect of 15 to 16 percentage points. This may be attributed to untrained members believing that trained leaders have gained relevant skills (trust in competence) and that trained leaders are less likely to privately capture rents (trust in motives). We further split these spillover effects into spillovers in RPOs where only leaders were invited (participated), RPOs where only members were invited (participated) and RPOs where both leaders and members were invited (participated). Results presented in Table 9 hint at the spillover effects in trust in leaders being most pronounced in RPOs where either only leaders or only members were invited (participated). Given the small sample size in the subsample containing only leaders $(\mathrm{N}=168)$, results for this subsample present inconclusive (see Table 10 .

\footnotetext{
${ }^{35}$ The average baseline trust levels range from 0.62 for general trust in members to 0.71 for trust in leaders' integrity.
} 


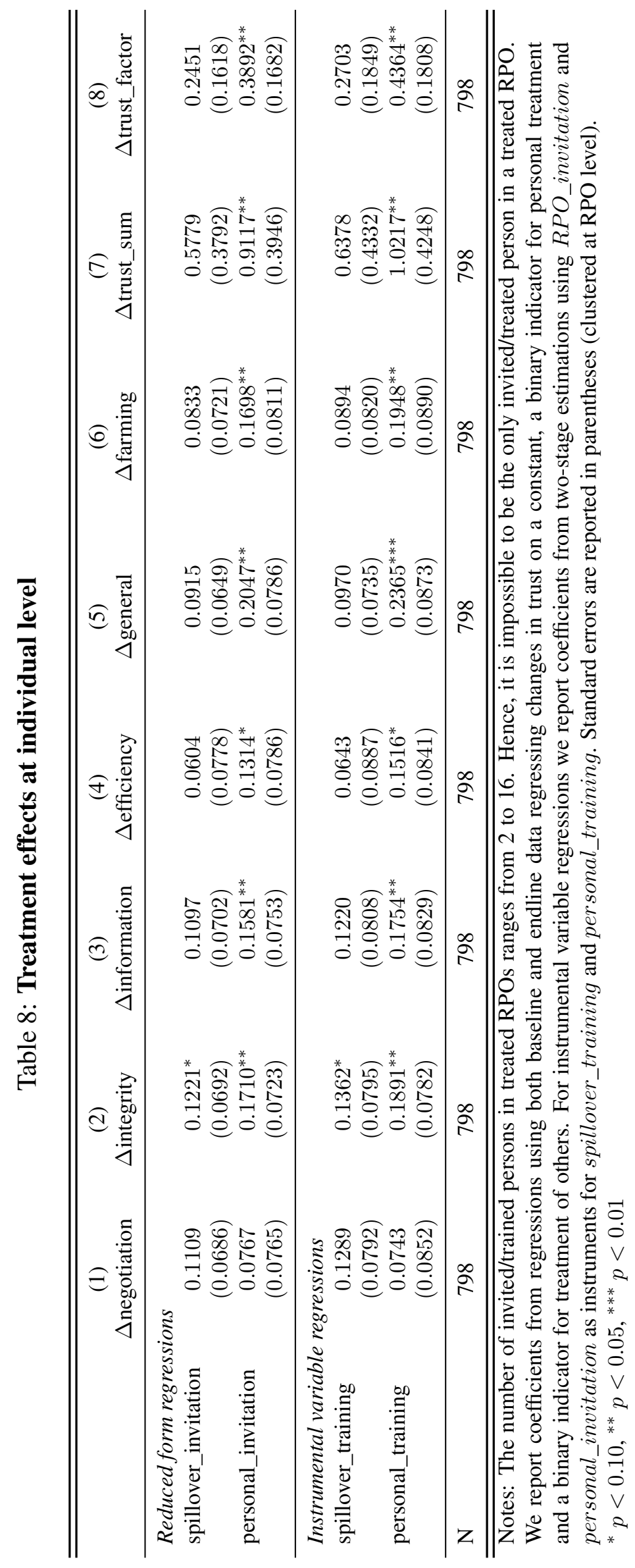




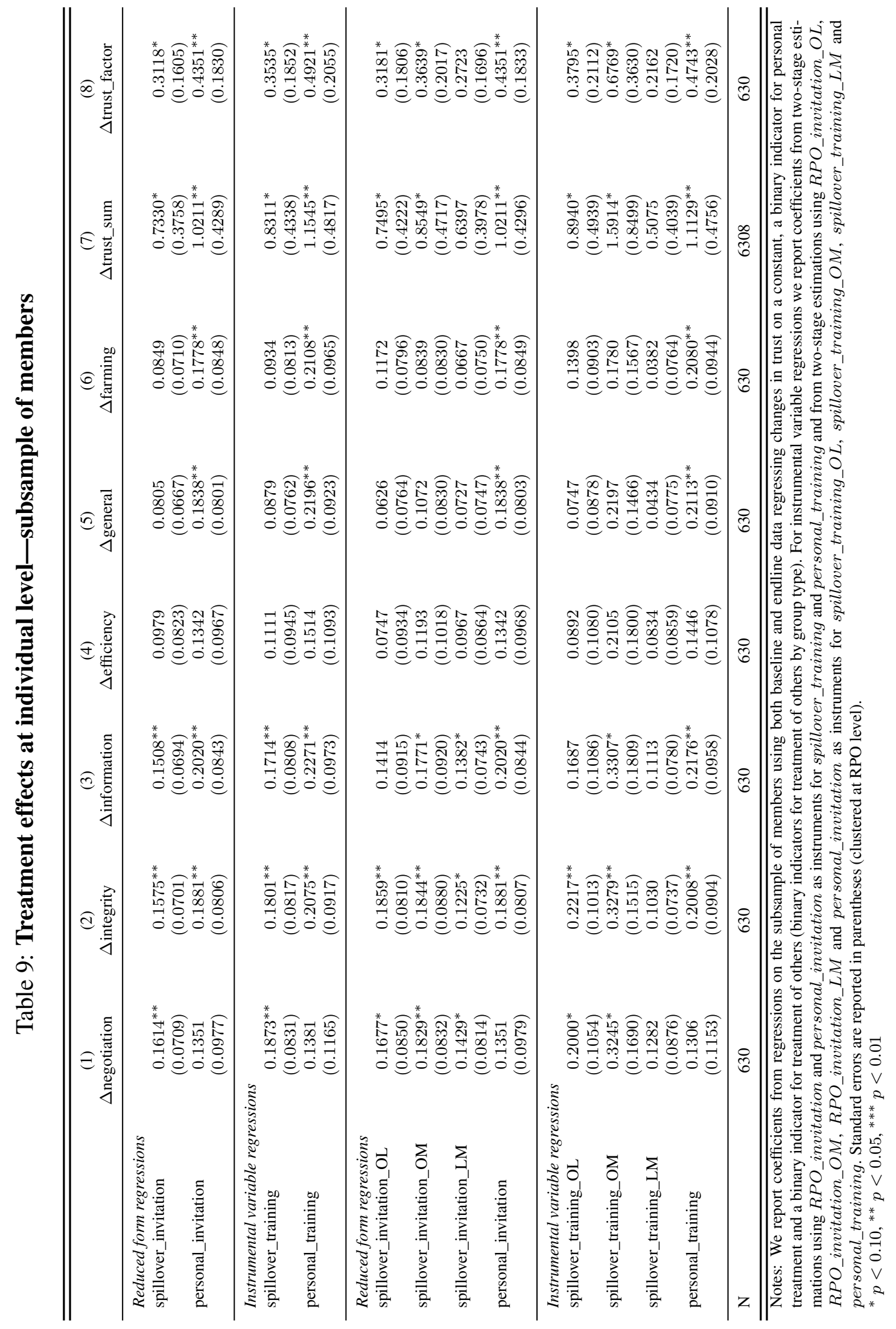




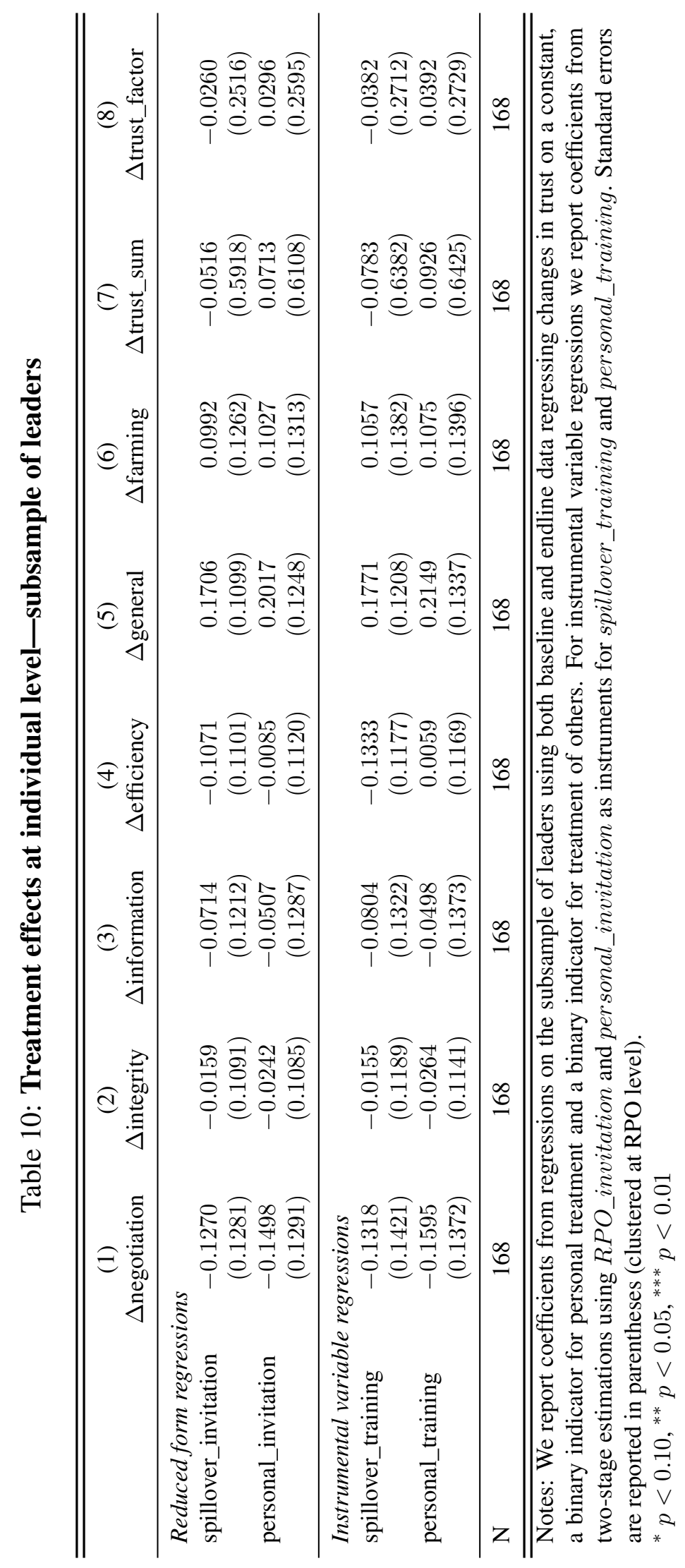


We run similar robustness checks on the full sample of 798 farmers as we did for the treatment effects on RPO level. First, we enlarge the model in first differences by allowing for onion-specific and rice-specific time trends and by controlling for the number of invited/trained persons per RPO. Qualitatively, results remain unchanged compared to the model in first differences without covariates. Second, we estimate ANCOVA specifications without covariates, with controls for onion and rice cultivation and with controlling for the number of invited/trained persons per RPO. Results are similar to those from the differencein-differences estimations and robust to controlling for onion and rice cultivation and to controlling for the number of invitees/participants. For details on these robustness checks, see Appendix B.4.

Besides having an impact on intra-RPO trust in both members and leaders, the training intervention may have also affected farmers' perception of their RPO. Data about the true and perceived level of information is scarce in our data set. We have information on how well farmers know their own RPO, namely whether they believe to know how many members their RPO has. This question was only included in the endline survey. In Table 11 we report the percentage of farmers stating that they know the size of their RPO by intended treatment status. On average, farmers from invited RPOs feel significantly better informed about the size of their RPO than farmers in the control group. This difference is dominated by farmers who were personally invited, but also non-invited farmers in the treatment group fare better than farmers in the control group. Apparently, the training was able to provide farmers with information they were previously lacking. In line with this, we find that farmers in invited RPOs appear better informed about the potential benefits of an efficiently working RPO, and also a significant difference when looking at the evaluation of the actual RPOs (see Table 11). Farmers from invited RPOs are significantly more confident than farmers from the control group that their RPO can help to overcome hindrances that they encounter when selling individually. 
Table 11: Perception of RPO at endline by intended treatment status

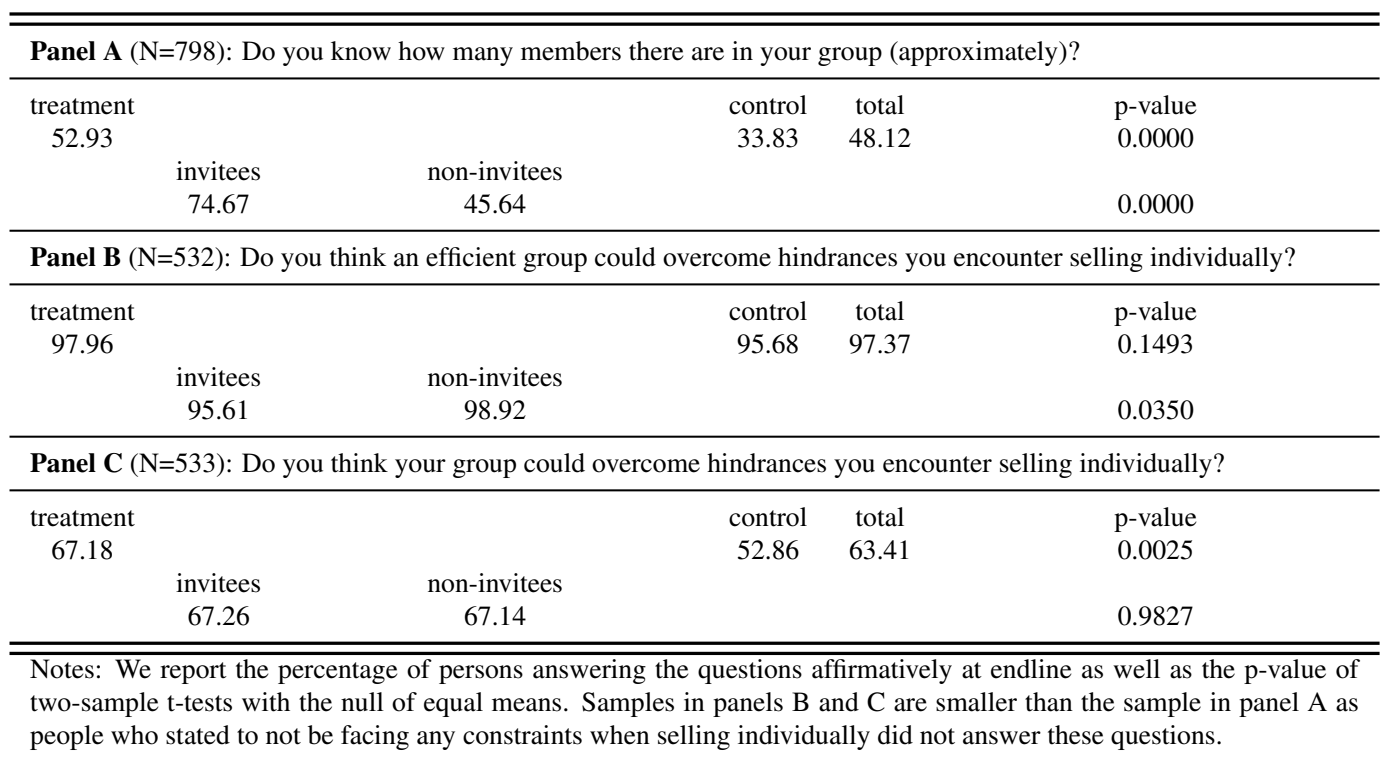

\section{Concluding remarks}

Although many positive examples from both developed and developing countries exist, many RPOs still struggle to offer the type of commercialization services that would lead to higher output prices for their members. In this paper, we have argued that trust in leaders' motives and competence as well as trust in members are crucial for successful collective commercialization as a form of collective action.

We conduct a cluster-randomized controlled trial in the context of RPOs in Senegal. We randomly invited members and/or leaders to participate in a threeday training to induce members and leaders to coordinate towards successful collective commercialization. The training itself consisted of three days of interactive discussion on the benefits, conduct and constraints of collective commercialization. In all treated RPOs, a general assembly was convened shortly after the training to discuss its content with non-participants.

We find a positive treatment effect of the training on both trust in leaders and trust in members. For trust in leaders, the effect is especially pronounced for trust in leaders' integrity and their informational advantage. Moreover, results suggest a strong spillover effect on non-treated members for trust in leaders, i.e., that the sizable positive average treatment effect is not to be attributed solely to personal invitation. This may be attributed to untrained members believing that 
trained leaders have gained relevant skills (trust in competence) and that trained leaders are less likely to privately capture rents (trust in motives). These results are robust to the inclusion of different covariates and to different specifications of the underlying model.

These findings suggest that relatively soft and non-costly interventions such as a group training appear to be able to positively affect intra-RPO trust and the farmer's perception of coordination towards successful collective action. Furthermore, social capital is often thought to increase with use, i.e., it is thought of as being self-reinforcing when reciprocity connects people leading to increased trust and confidence (Pretty and Ward, 2001). Thus, the training may well have been the starting point for more collective endeavors to come. Bernard et al. (2014) show for a subsample of groundnut farmers that the training intervention indeed had a positive effect on the quantity of produce commercialized collectively through the RPOs. While being the motivation for this research, collective commercialization is only one dimension along which smallholders can benefit from the training intervention. Smallholders can benefit from the newly gained intra-RPO trust in many ways; RPOs also engage in various other joint activities aside from collective commercialization all of which require trust among members and leaders. For example, RPOs lend farming equipment or provide credit to their members. In case of the rice farmers, there is good case to believe that they benefit from increased trust when jointly managing irrigation systems. With well-developed social capital, local water-users' groups are able to use existing resources more efficiently than individuals working alone or in competition. The same holds true for forest management practiced by some RPOs (Pretty and Ward, 2001). 


\section{References}

Agrawal, A. (2001). Common Poperty Institutions and Sustainable Governance of Resources. World Development, 29(10):1649-1672.

Arcand, J.-L. (2002). Producer Organizations in Burkina Faso and Sénégal: A Synthesis of Case Studies in Twenty Villages. Mimeo, CERDI - CNRS, Clermont Ferrand.

Bellemare, C. and Kröger, S. (2007). On representative social capital. European Economic Review, 51(1):183-202.

Bernard, T., Collion, H., de Janvry, A., Rondot, P., and Sadoulet, E. (2008a). Do Village Organizations Make a Difference in African Rural Development? A Study for Senegal and Burkina Faso. World Development, 36(11):2188-2204.

Bernard, T., Sene, L., Viceisza, A., and Wouterse, F. (2014). Leaders needed. Experimental Evidence from Rural Producer Organizationations in Senegal. Mimeo, International Fool Policy Research Institute, Washington, D.C.

Bernard, T., Spielman, D., Taffesse, A., and Gabre-Madhin, E. (2010). Cooperatives for Staple Crop Marketing. Evidence from Ethiopia. Research Monograph 164, International Food Policy Research Institute, Washington, D. C.

Bernard, T., Taffesse, S., and Gabre-Madhin, E. (2008b). Impact of cooperatives on smallholders' commercialization behaviour: evidence from Ethiopia. Agricultural Economics, 39(2):147-161.

Bernard, T. and Wouterse, F. (2015). Triggering collective action: Evidence from farmer groups in Senegal. Mimeo, International Food Policy Research Institute, Washington, D.C.

Beugelsdijk, S. (2006). A Note on the Theory and Measure of Trust in Explaining Differences in Economic Growth. Cambridge Journal of Economics, 30(3):371-387.

Bloom, N., Eifert, B., Mahajan, A., McKenzie, D., and Roberts, J. (2013). Does Management Matter? Evidence from India. The Quarterly Journal of Economics, 128(1):1-51.

Buck, S. and Alwang, J. (2011). Agricultural extension, trust, and learning: results from economic experiments in Ecuador. Agricultural Economics, 42(6):685-699.

Collier, P. (2002). Social capital and poverty: a microeconomic perspective. In Grootaert, C. and van Bastelaer, T., editors, The role of social capital in development: an empirical assessment, chapter 1, pages 19-41. Cambridge University Press, Cambridge. 
Devaux, A., Horton, D., Velasco, C., Thiele, G., López, G., Bernet, T., Reinoso, I., and Ordinola, M. (2009). Collective action for market chain innovation in the Andes. Food Policy, 34(1):31-38.

Durlauf, S. (2002). On the Empirics of Social Capital. The Economic Journal, 112(483):459-479.

Fafchamps, M. and Hill, R. (2005). Selling at the Farmgate or Traveling to Market. American Journal of Agricultural Economics, 87(3):717-734.

Fehr, E., Fischbacher, U., von Rosenbladt, B., Schupp, J., and Wagner, G. (2002). A nationwide laboratory - Examining trust and trustworthiness by integrating behavioural experiments into representative surveys. Schmollers Jahrbuch, 122:519-542.

Gambetta, D. (2003). Can We Trust Trust? In Ostrom, E. and Ahn, T. K., editors, Foundations of Social Capital, chapter 13, pages 274-290. Edward Elgar, Northampton, MA.

Glaeser, E., Laibson, D., Scheinkman, J., and Soutter, C. (2000). Measuring trust. Quarterly Journal of Economics, 115(3):811-846.

Hill, R. V., Maruyama, E., Olapade, M., and Frölich, M. (2014). Strengthening producer organizations to increase market access of smallholder farmers in Uganda. Mimeo.

Imbens, G. W. and Wooldridge, J. M. (2009). Recent Developments in the Econometrics of Program Evaluation. Journal of Economic Literature, 47(1):5-86.

Kodama, Y. (2007). New Role of Cooperatives in Ethiopia: The Case of Ethiopian Coffee Farmers Cooperatives. African Study Monographs, 35:87-109.

Kramer, R. M. (1999). Trust and Distrust in Organizations: Emerging Perspectives, Enduring Questions. Annual Review of Psychology, 50:569-598.

Landmann, A. and Frölich, M. (2015). Can health-insurance help prevent child labor? An impact evaluation from Pakistan. Journal of Health Economics, 39:51-59.

Map Maker Ltd (2014). Map Library: Sengal Level 1 divisions latitude and longitude coordinates. Retrieved on 6 March 2015 from http://www. mapmakerdata.co.uk.s3-website-eu-west-1.amazonaws. com/library/stacks/Africa/Senegal/index.htm.

Markelova, H., Meinzen-Dick, R., Hellin, J., and Dohrn, S. (2009). Collective action for smallholder market access. Food Policy, 34(1):1-7. 
Masakure, O. and Henson, S. (2005). Why Do Small-Scale Producers Choose to Produce under Contract? Lessons from Nontraditional Vegetable Exports from Zimbabwe. World Development, 33(10):1721-1733.

McKenzie, D. (2012). Beyond Baseline and Follow-Up: The Case for More T in Experiments. Journal of Development Economics, 99(2):210-221.

Mercoiret, M.-R. (n.d.). Enhancing the Capacities of Rural Producer Organisations: The case of the Agricultural Services and Producer Organisations Support Program (PSAOP) - Senegal. Report, World Bank, Washington, D.C.

Möllering, G., Bachmann, R., and Lee, S. H. (2004). Introduction: Understanding organizational trust-foundations, constellations, and issues of operationalisation. Journal of Managerial Psychology, 19(6):556-570.

Naef, M. and Schupp, J. (2009). Measuring Trust: Experiments and Surveys in Contrast and Combination. Discussion Paper 4087, IZA, Bonn.

Narrod, C., Roy, D., Okello, J., Avendaño, B., Rich, K., and Thorat, A. (2009). Public-private partnerships and collective action in high value fruit and vegetable supply chains. Food Policy, 34(1):8-15.

North, D. C. (1990). Institutions, Institutional Change, and Economic Performance. Cambridge University Press, Cambridge.

Ostrom, E. and Ahn, T. K. (2003). Introduction. In Ostrom, E. and Ahn, T. K., editors, Foundations of Social Capital, pages xi-xxxix. Edward Elgar, Northampton, MA.

Poulton, C., Dorward, A., and Kydd, J. (2010). The Future of Small Farms: New Directions for services, Institutions, and Intermediation. World Development, 38(10):1413-1428.

Pretty, J. and Ward, H. (2001). Social Capital and the Environment. World Development, 29(2):209-227.

Putnam, R. D. (1993). The Prosperous Community: Social Capital and Public Life. American Prospect, 13:35-42.

Réseau des Organisations Paysannes et Pastorales du Sénégal (2008). Coopératives au Sénégal. Retrieved on 11 September 2014 from http://www. resopp-sn.org/rubrique.php3?id_rubrique=18.

Rondot, P. and Collion, M.-H. (2001). Agricultural Producer Organizations: Their Contribution to Rural Capacity Building and Poverty Reduction. Workshop Report, World Bank, Washington, D.C. 
Sapienza, P., Toldra, A., and Zingales, L. (2007). Understanding trust. Working Paper 13387, National Bureau of Economic Research, Washington, D.C.

Seppänen, R., Blomqvist, K., and Sundqvist, S. (2007). Measuring interorganizational trust-a criticial review of the empirical research in 1990-2003. Industrial Marketing Management, 36:249-265.

Shiferaw, B., Hellin, J., and Muricho, G. (2011). Improving market access and agricultural productivity growth in Africa: what role for producer organizations and collective action institutions? Food Security, 3(4):475-489.

Shiferaw, B., Obare, G., and Muricho, G. (2008). Rural market imperfections and the role of institutions in collective action to improve markets for the poor. Natural Resources Forum, 32(1):25-38.

Sobel, J. (2002). Can we trust social capital? Journal of Economic Literature, 40(1):139-154.

Stockbridge, M., Dorward, A., and Kydd, J. (2003). Farmer Organisations For Market Access: Learning from Success. Briefing Paper, Department for International Development, London.

Tefft, J. (2004). Building on Success in African Agriculture: Mali's White Revolution: Smallholder Cotton from 1960 to 2003. 2020 Vision Focus Brief 12, International Food Policy Research Institute, Washington, D.C.

The World Bank (2008). World Development Report 2008: Agriculture for Development. Report, The World Bank, Washington, D.C.

Tschannen-Moran, M. and Hoy, W. K. (2000). A Multidisciplinary Analysis of the Nature, Meaning, and Measure of Trust. Review of Educational Research, 70(4):547-593.

Twyman, M., Harvey, N., and Harries, C. (2008). Trust in motives, trust in competence: Separate factors determining the effectiveness of risk communication. Judgment and Decision Making, 3(1):111-120.

Wollni, M. and Zellner, M. (2007). Do farmers benefit from participating in specialty markets and cooperatives? The case of coffee marketing in Costa Rica. Agricultural Economics, 37(2-3):243-248.

Yamagishi, T. (2001). Trust as a Form of Social Intelligence. In Cook, C., editor, Trust in Society, pages 121-147. Russel Sage Foundation, New York.

Yamagishi, T., Kikuchi, M., and Kosugi, M. (1999). Trust, gullibility, and social Intelligence. Asian Journal of Social Psychology, 2(1):145-161. 


\section{Appendix}

\section{A Definition of variables}

\begin{tabular}{|c|c|c|}
\hline Variable & Wave & Description \\
\hline age & baseline & age of the respondent in years \\
\hline bicycles & endline & number of bicycles the respondent owns \\
\hline contribution & endline & $\begin{array}{l}\text { binary variable equal to one if the respondent has delivered } \\
\text { agricultural produce for collective commercialization to the }\end{array}$ \\
\hline distance to market & endline & $\begin{array}{l}\text { RPO in the agricultural season } 2010 / 2011 \text {, zero otherwise } \\
\text { distance to nearest crop market in kilometers }\end{array}$ \\
\hline distance to storage & baseline & $\begin{array}{l}\text { distance to the RPO's storage facilities (meeting place, if } \\
\text { there are no storage facilities) in walking minutes }\end{array}$ \\
\hline efficiency & both & $\begin{array}{l}\text { Binary variable equal to one if the respondent fully agrees } \\
\text { to the following statement, zero otherwise: "If I invest my } \\
\text { money or my produce in the RPO, it will be used efficiently" }\end{array}$ \\
\hline efficiency_ordinal & both & $\begin{array}{l}\text { trust in leaders' efficiency measured on a scale from } 1 \text { (low- } \\
\text { est) to } 4 \text { (highest) based on the level of agreement to the fol- } \\
\text { lowing statement: "If I invest my money or my produce in } \\
\text { the RPO, it will be used efficiently". }\end{array}$ \\
\hline farming & both & $\begin{array}{l}\text { binary variable equal to one if the respondent fully agrees } \\
\text { to the following statement, zero otherwise: "I can trust the } \\
\text { people from my RPO to look after my field during an absence } \\
\text { of two months" }\end{array}$ \\
\hline farming_ordinal & both & $\begin{array}{l}\text { farming-specific trust in members measured on a scale from } 1 \\
\text { (lowest) to } 4 \text { (highest) based on the level of agreement to the } \\
\text { following statement: "I can trust the people from my RPO to } \\
\text { look after my field during an absence of two months" }\end{array}$ \\
\hline general & both & $\begin{array}{l}\text { binary variable equal to one if the respondent fully agrees } \\
\text { to the following statement, zero otherwise: "The majority of } \\
\text { people from the RPO are trustworthy" }\end{array}$ \\
\hline general_ordinal & both & $\begin{array}{l}\text { general trust in members measured on a scale from } 1 \text { (lowest) } \\
\text { to } 4 \text { (highest) based on the level of agreement to the following } \\
\text { statement: "The majority of people from the RPO are trust- } \\
\text { worthy" }\end{array}$ \\
\hline groundnut & both & $\begin{array}{l}\text { binary variable equal to one if farmers organized in the RPO } \\
\text { cultivate groundnuts, zero otherwise }\end{array}$ \\
\hline hectares & baseline & size of managed land in hectares \\
\hline heterogeneity & endline & $\begin{array}{l}\text { binary variable equal to one if farmers organized in the RPO } \\
\text { belong to more than one ethnicity, zero if they all belong to } \\
\text { the same ethnicity }\end{array}$ \\
\hline household size & baseline & household size \\
\hline information & both & $\begin{array}{l}\text { binary variable equal to one if the respondent fully agrees to } \\
\text { the following statement, zero otherwise: "If the RPO's board } \\
\text { says that I can achieve better prices if I wait a little, they do } \\
\text { so because they have adequate information" }\end{array}$ \\
\hline
\end{tabular}




\begin{tabular}{|c|c|c|}
\hline Variable & Wave & Description \\
\hline information_ordinal & both & $\begin{array}{l}\text { trust in leaders' informational advantage measured on a } \\
\text { scale from } 1 \text { (lowest) to } 4 \text { (highest) based on the level of } \\
\text { agreement to the following statement: "If the RPO's board } \\
\text { says that I can achieve better prices if I wait a little, they do } \\
\text { so because they have adequate information" }\end{array}$ \\
\hline integrity & both & $\begin{array}{l}\text { binary variable equal to one if the respondent fully agrees to } \\
\text { the following statement, zero otherwise: "Board members } \\
\text { defend the RPO's interests and their own interests in equal } \\
\text { measure" }\end{array}$ \\
\hline integrity_ordinal & both & $\begin{array}{l}\text { trust in leaders' integrity measured on a scale from } 1 \text { (low- } \\
\text { est) to } 4 \text { (highest) based on the level of agreement to the } \\
\text { following statement: "Board members defend the RPO's in- } \\
\text { terests and their own interests in equal measure" }\end{array}$ \\
\hline literate & baseline & $\begin{array}{l}\text { binary variable equal to one if the respondent is literate, zero } \\
\text { otherwise }\end{array}$ \\
\hline male & baseline & $\begin{array}{l}\text { binary variable equal to one if the respondent is male, zero } \\
\text { if she is female }\end{array}$ \\
\hline member & baseline & $\begin{array}{l}\text { binary variable equal to one if the respondent is a member, } \\
\text { zero if }(s) \text { he is a leader }\end{array}$ \\
\hline members' initiative & baseline & $\begin{array}{l}\text { binary variable equal to one if the creation initiative came } \\
\text { from group members, zero otherwise }\end{array}$ \\
\hline motorcycles & endline & number of motorcycles the respondent owns \\
\hline negotiation & both & $\begin{array}{l}\text { binary variable equal to one if the respondent fully agrees to } \\
\text { the following statement, zero otherwise: "The RPO's board } \\
\text { is capable of negotiating better prices for our products than } \\
\text { I am capable of myself" }\end{array}$ \\
\hline negotiation_ordinal & both & $\begin{array}{l}\text { trust in leaders' negotiation skills measured on a scale from } \\
1 \text { (lowest) to } 4 \text { (highest) based on the level of agreement to } \\
\text { the following statement: "The RPO's board is capable of } \\
\text { negotiating better prices for our products than I am capable } \\
\text { of myself" }\end{array}$ \\
\hline onion & both & $\begin{array}{l}\text { binary variable equal to one if farmers organized in the RPO } \\
\text { cultivate onions, zero otherwise }\end{array}$ \\
\hline personal_invitation & both & $\begin{array}{l}\text { binary variable equal to one if the respondent was invited, } \\
\text { zero otherwise }\end{array}$ \\
\hline personal_training & both & $\begin{array}{l}\text { binary variable equal to one if the respondent participated } \\
\text { in the training, zero otherwise }\end{array}$ \\
\hline phone & endline & $\begin{array}{l}\text { binary variable equal to one if any of the respondent's } \\
\text { household's members owns a mobile phone, zero otherwise }\end{array}$ \\
\hline related to leader & baseline & $\begin{array}{l}\text { binary variable equal to one if the respondent is related to a } \\
\text { leader }\end{array}$ \\
\hline rice & both & $\begin{array}{l}\text { binary variable equal to one if farmers organized in the RPO } \\
\text { cultivate rice, zero otherwise }\end{array}$ \\
\hline$R P O \_$invitation & both & $\begin{array}{l}\text { binary variable equal to one if at least one member or at least } \\
\text { one leader of the RPO has been invited to participate in the } \\
\text { training intervention, zero if nobody was invited }\end{array}$ \\
\hline
\end{tabular}




\begin{tabular}{|c|c|c|}
\hline Variable & Wave & Description \\
\hline$R P O \_$invitation_LM & both & $\begin{array}{l}\text { binary variable equal to one if at least one member and } \\
\text { at least one leader of the RPO has been invited to par- } \\
\text { ticipate in the training intervention, zero otherwise }\end{array}$ \\
\hline$R P O \_i n v i t a t i o n \_O L$ & both & $\begin{array}{l}\text { binary variable equal to one if at least one leader and } \\
\text { no member of the RPO has been invited to participate } \\
\text { in the training intervention, zero otherwise }\end{array}$ \\
\hline$R P O \_$invitation_OM & both & $\begin{array}{l}\text { binary variable equal to one if at least one member and } \\
\text { no leader of the RPO has been invited to participate in } \\
\text { the training intervention, zero otherwise }\end{array}$ \\
\hline$R P O \_$training & both & $\begin{array}{l}\text { binary variable equal to one if at least one member or at } \\
\text { least one leader of the RPO participated in the training } \\
\text { intervention, zero if nobody participated }\end{array}$ \\
\hline sales & endline & $\begin{array}{l}\text { binary variable equal to one if the RPO engaged in col- } \\
\text { lective sales in the agricutural season } 2010 / 2011 \text {, i.e., if } \\
\text { at least one farmer sold produce to the RPO, zero if it } \\
\text { did not }\end{array}$ \\
\hline savings in bank & endline & $\begin{array}{l}\text { binary variable equal to one if the respondent has a sav- } \\
\text { ings account with a bank, zero otherwise }\end{array}$ \\
\hline savings in $M F I$ & endline & $\begin{array}{l}\text { binary variable equal to one if the respondent has a } \\
\text { savings account with a société d'assurance, mutuelle, } \\
\text { caisse or microfinance organization, zero otherwise }\end{array}$ \\
\hline size & baseline & number of farmers that are part of the RPO \\
\hline spillover_invitation & both & $\begin{array}{l}\text { binary variable equal to one if somebody other than the } \\
\text { respondent was invited, zero otherwise }\end{array}$ \\
\hline spillover_invitation_LM & both & $\begin{array}{l}\text { binary variable equal to one if somebody other than the } \\
\text { respondent was invited under the "leaders and mem- } \\
\text { bers" scheme, zero otherwise }\end{array}$ \\
\hline spillover_invitation_OL & both & $\begin{array}{l}\text { binary variable equal to one if some leader other than } \\
\text { the respondent was invited under the "leaders only" } \\
\text { scheme, zero otherwise }\end{array}$ \\
\hline spillover_invitation_OM & both & $\begin{array}{l}\text { binary variable equal to one if some member other than } \\
\text { the respondent was invited under the "members only" } \\
\text { scheme, zero otherwise }\end{array}$ \\
\hline spillover_training & both & $\begin{array}{l}\text { binary variable equal to one if somebody other than the } \\
\text { respondent participated in the training, zero otherwise }\end{array}$ \\
\hline spillover_training_LM & both & $\begin{array}{l}\text { binary variable equal to one if somebody other than the } \\
\text { respondent participated in the training under the "lead- } \\
\text { ers and members" scheme, zero otherwise }\end{array}$ \\
\hline spillover_training_OL & both & $\begin{array}{l}\text { binary variable equal to one if some leader other than } \\
\text { the respondent participated in the training under the } \\
\text { "leaders only" scheme, zero otherwise }\end{array}$ \\
\hline spillover_training_OM & both & $\begin{array}{l}\text { binary variable equal to one if some member other than } \\
\text { the respondent participated in the training under the } \\
\text { "members only" scheme, zero otherwise }\end{array}$ \\
\hline trust_factor & both & factor variable containing the six binary trust measures \\
\hline trust_sum & both & sum over the six binary trust measures \\
\hline vehicles & endline & $\begin{array}{l}\text { number of motorized vehicles other than motorcycles } \\
\text { the respondent owns }\end{array}$ \\
\hline
\end{tabular}




\begin{tabular}{|c|c|c|}
\hline Variable & Wave & Description \\
\hline year of creation & baseline & year in which the RPO was created \\
\hline year joined & baseline & year in which the respondent joined the RPO \\
\hline number_invited & both & $\begin{array}{l}\text { number of people other than the respondent who were } \\
\text { invited from a RPO }\end{array}$ \\
\hline number_invited_leaders & both & $\begin{array}{l}\text { number of leaders other than the responden twho were } \\
\text { invited from a RPO }\end{array}$ \\
\hline number_invited_members & both & $\begin{array}{l}\text { number of members other than the respondent who } \\
\text { were invited from a RPO }\end{array}$ \\
\hline number_trained & both & $\begin{array}{l}\text { number of people other than the respondent from a } \\
\text { RPO who participated in the training }\end{array}$ \\
\hline number_trained_leaders & both & $\begin{array}{l}\text { number of leaders from a RPO who participated in the } \\
\text { training }\end{array}$ \\
\hline number_trained_members & both & $\begin{array}{l}\text { number of members from a RPO who participated in } \\
\text { the training }\end{array}$ \\
\hline
\end{tabular}

Notes: Data collection took place November/December 2011 (baseline) and January/February 2012 (endline). 


\section{B Supplementary analyses}

In this appendix we provide additional analyses on selected issues discussed in the paper.

\section{B.1 One-sided noncompliance}

While invitations were distributed according to the randomization protocol, onesided noncompliance regarding training participation was frequent. While none of the control RPOs participated in the training, some of the invited RPOs chose not to participate. From those RPOs that did participate, not always the exact farmers that had personally been invited to the training participated, sometimes others came to the training instead. In the empirical analysis, we deal with this by estimating intention-to-treat effects, i.e. the treatment effect of the invitation, and by estimating treatment effects of the training by instrumenting for the participation using the invitation as instrument. Tables B.1 and B.2 provide details on the one-sided noncompliance.

In Table B.1 we provide details based on the distribution of invitations while we consider actual participation in the training in Table B.2. In Table B.1 we report the intended distribution of 798 interviewed farmers from 73 RPOs on 50 invited and 23 non-invited RPOs, and the intended distribution of 597 interviewed farmers from 50 invited RPOs on 150 invitees and 447 non-invitees. Further, we report how the invitations were allocated to RPOs in which only leaders (OL), only members $(\mathrm{OM})$, or both leaders and members (LM) were invited. We report both the number of farmers and the number of RPOs (in parentheses).

In Table B.2 we report the actual distribution of 798 interviewed farmers from 73 RPOs on 44 treated and 23 non-treated RPOs, and the distribution of 534 interviewed farmers from 44 treated RPOs on 142 trained and 392 non-trained farmers. Further, we report how the participation was allocated to RPOs in which only leaders (OL), only members (OM), or both leaders and members (LM) were trained. We report both the number of farmers and the number of RPOs (in parentheses). 
Table B.1: Sample by intended treatment status

\begin{tabular}{|c|c|c|c|c|c|c|c|c|c|c|}
\hline $\begin{array}{l}\text { treatment } \\
\qquad 597 \\
(50)\end{array}$ & & & & & & & & & $\begin{array}{c}\text { control } \\
201 \\
(23)\end{array}$ & $\begin{array}{l}\text { total } \\
798 \\
(73)\end{array}$ \\
\hline \multirow{5}{*}{$(50)$} & invitees & & & & non-invitees & & & & & \\
\hline & 150 & & & & 447 & & & & & \\
\hline & & $\mathrm{OL}$ & OM & LM & & $\mathrm{OL}$ & OM & LM & & \\
\hline & & 22 & 29 & 99 & & 115 & 131 & 201 & & \\
\hline & & (12) & (15) & (23) & & & & & & \\
\hline
\end{tabular}

Notes: We report the intended distribution of 798 interviewed individuals from 73 RPOs on treatment and control group, and the intended distribution of 597 interviewed individuals from 50 treatment RPOs on invitees and non-invitees from different types of groups ( $\mathrm{OM}-$ only members were invited, OL—only leaders were invited, LM—both members and leaders were invited). Values in parentheses are the number of RPOs.

Table B.2: Sample by actual treatment status

\begin{tabular}{|c|c|c|c|c|c|c|c|c|c|c|}
\hline \multirow[t]{4}{*}{$\begin{array}{c}\text { treatment } \\
534 \\
(44)\end{array}$} & & & & & & & & & $\begin{array}{c}\text { control } \\
264 \\
(29)\end{array}$ & $\begin{array}{c}\text { total } \\
798 \\
(73)\end{array}$ \\
\hline & $\begin{array}{c}\text { trainees } \\
142\end{array}$ & & & & $\begin{array}{c}\text { non-trainees } \\
392\end{array}$ & & & & & \\
\hline & & OL & $\mathrm{OM}$ & LM & & OL & $\mathrm{OM}$ & LM & & \\
\hline & & $\begin{array}{c}20 \\
(10)\end{array}$ & $\begin{array}{l}16 \\
(9)\end{array}$ & $\begin{array}{l}106 \\
(25)\end{array}$ & & 95 & 86 & 211 & & \\
\hline
\end{tabular}

Notes: We report the actual distribution of 798 interviewed individuals from 73 RPOs on treatment and control group, and the distribution of 534 interviewed individuals from 44 treatment RPOs on trainees and non-trainees from different types of groups $(\mathrm{OM}$-only members were trained, OL-only leaders were trained, LM—both members and leaders were trained). Values in parentheses are the number of RPOs. 


\section{B.2 Descriptive statistics for ordinal measures of trust}

Originally, responses to all trust survey questions were recorded on a four-point Likert-type scale. The items to choose from are (1) "Do not agree at all", (2) "Do not really agree", (3) "Agree", and (4) "Fully agree". However, given that the average trust levels at baseline are well above 3 for all measures of trust, we use binary variables as regressands in the empirical analysis which are equal to one if respondents fully agree with one of the asked statements. Here, we report additional descriptive statistics for trust measures using the original coding.

In Table B.3 we show that the assignment of the invitations is also independent of ordinal trust measures at baseline. The two-sample Wilcoxon rank-sum tests with the null of equal means in control and treatment groups at baseline reveal no significant differences.

Table B.3: Balancing tests of ordinal trust measures at RPO level

\begin{tabular}{lccccr}
\hline \hline \multicolumn{1}{c}{ Variable } & Mean & $\begin{array}{c}\text { Standard } \\
\text { deviation }\end{array}$ & $\begin{array}{c}\text { Mean in } \\
\text { control group } \\
(\mathrm{N}=23)\end{array}$ & $\begin{array}{c}\text { Mean in } \\
\text { treatment group } \\
(\mathrm{N}=50)\end{array}$ & Difference \\
\hline negotiation_ordinal & 3.41 & 0.37 & 3.34 & 3.44 & -0.10 \\
integrity_ordinal & 3.51 & 0.42 & 3.51 & 3.50 & 0.01 \\
information_ordinal & 3.54 & 0.34 & 3.60 & 3.51 & 0.09 \\
efficiency_ordinal & 3.50 & 0.42 & 3.48 & 3.51 & -0.03 \\
general_ordinal & 3.48 & 0.35 & 3.48 & 3.48 & -0.01 \\
farming_ordinal & 3.43 & 0.37 & 3.36 & 3.46 & -0.09 \\
\hline \hline
\end{tabular}

Notes: We report averages and standard deviations for the full sample of 73 RPOs, averages in the subsamples of RPOs in treatment and control group and results of two-sample Wilcoxon rank-sum tests with the null of equal means in control and treatment groups at baseline.

${ }^{*} p<0.10,{ }^{* *} p<0.05,{ }^{* * *} p<0.01$

Descriptive statistics reveal a positive impact of the intervention on ordinal measures of trust. In Table B.4 we report results of two-sample Wilcoxon ranksum tests with the null of equal means in ordinal trust in baseline and endline for invitees, non-invitees in invited RPOs and for non-invitees in non-invited RPOs. Moreover, we report two-sample Wilcoxon rank-sum tests with the null of equal means in ordinal trust for invitees and non-invitees in invited RPOs in both baseline and endline and for non-invitees in invited and non-invited RPOs in both baseline and endline. Results are similar to those when using binary trust measures (see Table 5). Invitees report higher levels of trust at endline compared to baseline for all ordinal measures for trust. Further indication of a positive di- 
rect treatment effect comes from the comparison of invitees with non-invitees from invited RPOs. While we observe no significant difference at baseline, we observe significant differences for all ordinal measures of trust in leaders but $n e$ gotiation_ordinal at endline. We also find descriptive evidence for a positive spill-over effect within invited RPOs. Comparing non-invitees from invited and non-invited RPOs, we find no significant differences at baseline. At endline, however, non-invitees in invited RPOs report significantly higher trust levels for all ordinal trust measures but efficiency_ordinal compared to non-invitees from noninvited RPOs.

Table B.4: Changes in ordinal trust by intended treatment status at RPO level

\begin{tabular}{|c|c|c|c|c|c|}
\hline Ordinal Trust Outcomes & Sample & $\mathrm{N}$ & Baseline (BL) & Endline(EL) & Diff. BL EL P-value \\
\hline \multirow[t]{5}{*}{ negotiation_ordinal } & A. Invitees & 150 & 3.49 & 3.53 & 0.1960 \\
\hline & B. Non-Invitees in $\mathrm{T}$ & 447 & 3.43 & 3.50 & 0.0029 \\
\hline & C. Non-Invitees in C & 201 & 3.35 & 3.24 & 0.6423 \\
\hline & Diff. A B P-value & & 0.3362 & 0.7642 & \\
\hline & Diff. B C P-value & & 0.4157 & 0.0008 & \\
\hline \multirow[t]{5}{*}{ integrity_ordinal } & A. Invitees & 150 & 3.59 & 3.59 & 0.4830 \\
\hline & B. Non-Invitees in $\mathrm{T}$ & 447 & 3.47 & 3.39 & 0.5975 \\
\hline & C. Non-Invitees in C & 201 & 3.49 & 3.21 & 0.0059 \\
\hline & Diff. A B P-value & & 0.1939 & 0.0236 & \\
\hline & Diff. B C P-value & & 0.7073 & 0.0168 & \\
\hline \multirow[t]{5}{*}{ information_ordinal } & A. Invitees & 150 & 3.57 & 3.71 & 0.0310 \\
\hline & B. Non-Invitees in $\mathrm{T}$ & 447 & 3.49 & 3.57 & 0.0499 \\
\hline & C. Non-Invitees in C & 201 & 3.59 & 3.43 & 0.1928 \\
\hline & Diff. A B P-value & & 0.3902 & 0.0531 & \\
\hline & Diff. B C P-value & & 0.2187 & 0.0661 & \\
\hline \multirow[t]{5}{*}{ efficiency_ordinal } & A. Invitees & 150 & 3.56 & 3.71 & 0.0698 \\
\hline & B. Non-Invitees in $\mathrm{T}$ & 447 & 3.49 & 3.48 & 0.8127 \\
\hline & C. Non-Invitees in C & 201 & 3.48 & 3.36 & 0.2672 \\
\hline & Diff. A B P-value & & 0.1990 & 0.0016 & \\
\hline & Diff. B C P-value & & 0.9008 & 0.1114 & \\
\hline \multirow[t]{5}{*}{ general_ordinal } & A. Invitees & 150 & 3.51 & 3.69 & 0.0123 \\
\hline & B. Non-Invitees in $\mathrm{T}$ & 447 & 3.46 & 3.52 & 0.2967 \\
\hline & C. Non-Invitees in C & 201 & 3.46 & 3.31 & 0.1068 \\
\hline & Diff. A B P-value & & 0.5608 & 0.0053 & \\
\hline & Diff. B C P-value & & 0.8025 & 0.0029 & \\
\hline \multirow[t]{5}{*}{ farming_ordinal } & A. Invitees & 150 & 3.47 & 3.63 & 0.0372 \\
\hline & B. Non-Invitees in $\mathrm{T}$ & 447 & 3.45 & 3.45 & 0.5494 \\
\hline & C. Non-Invitees in C & 201 & 3.36 & 3.22 & 0.1758 \\
\hline & Diff. AB P-value & & 0.6632 & 0.0166 & \\
\hline & Diff. BC P-value & & 0.3500 & 0.0036 & \\
\hline
\end{tabular}




\section{B.3 Robustness checks for treatment effects on RPO level}

We run several robustness checks to confirm our main findings reported in Section 5 .

First, we enlarge the model in first differences (see equations (1) and (4)) by allowing for onion-specific and rice-specific time trends (see Table B.5) and by controlling for the number of invited/trained persons per RPO (see Table B.6) ${ }^{36}$ Table B.5 shows results for regressing changes in trust on a binary treatment indicator, a binary indicator for rice cultivation, a binary indicator for onion cultivation and a constant. We report both intention-to-treat effects as well as results from two-stage regressions using invitation status as an instrument for training participation. We use RPO_invitation as instrument for RPO_training in Table B.5. The highly significant correlation coefficient between these two variables amounts to 0.8354 . Qualitatively, results remain unchanged compared to the model in first differences without covariates. We find a significantly positive treatment effect of the training of 12 to 13 percentage points on trust in leaders' integrity and their informational advantage. For the reduced form regressions, we provide conventional inference and randomization inference. We find a similar pattern as we did in our main analysis, $\mathrm{p}$-values for the randomization inference are smaller than those for the conventional inference for all regressions. Hence, for reasons of clarity, we refrain from presenting randomization inference in the following.

Table B.6 shows results for regressing changes in trust on a binary treatment indicator, the number of invited farmers and a constant. We also run a specification where we consider the number of invited members and the number of invited leaders. Again, we report both intention-to-treat effects as well as results from two-stage regressions using invitation status as an instrument for training participation. We use RPO_invitation and number_invited as instruments for RPO_trained and number_trained (highly significant correlation coefficients range between 0.6467 and 0.9054) as well as RPO_invitation, number_invited_ members and number_invited_leaders as instruments for RPO_trained, number_trained_members and number_trained_leaders in Table B.6 (highly significant correlation coefficients between 0.2458 and 0.9045). Qualitatively, results remain unchanged compared to our main results. The number of in-

\footnotetext{
${ }^{36}$ Note that when including covariates to the model in first differences, it is no longer equivalent to a fixed effects model.
} 
vited/trained persons has no additional effect on trust outcomes on top of the effect of the binary treatment measure. We find a significantly positive intentionto-treat effect of 14 to 16 percentage points on trust in leaders' integrity and their informational advantage. 


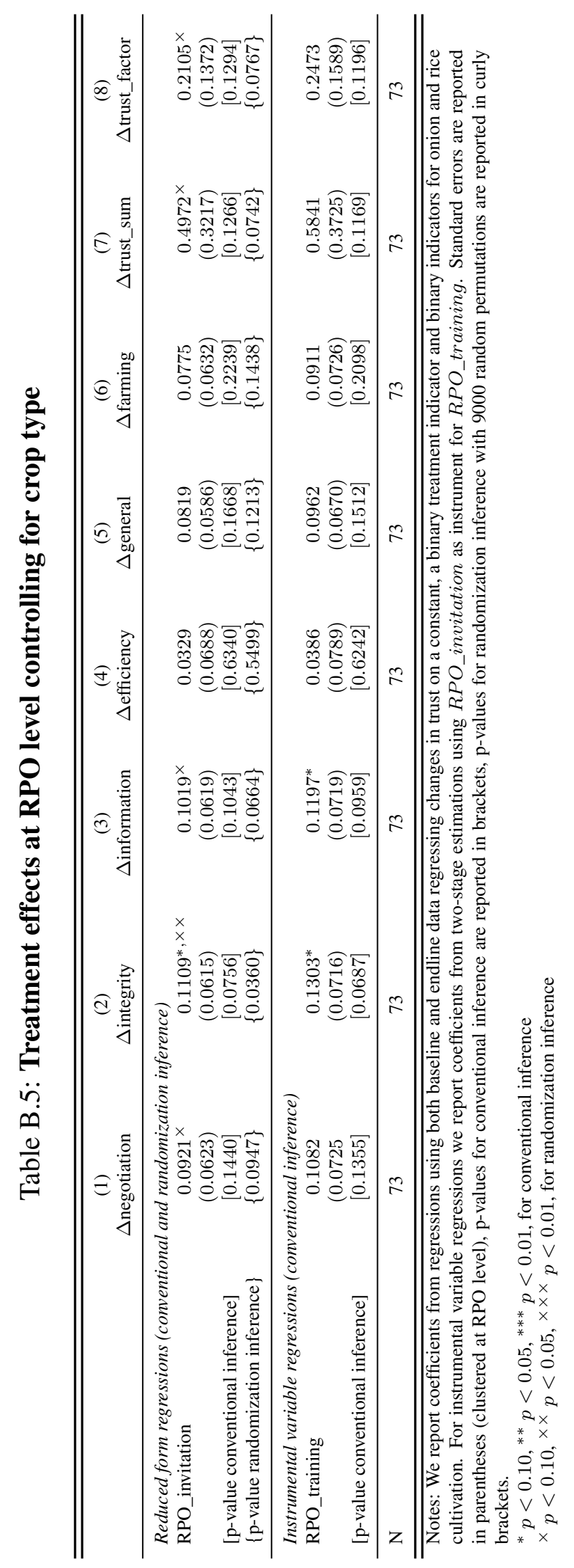




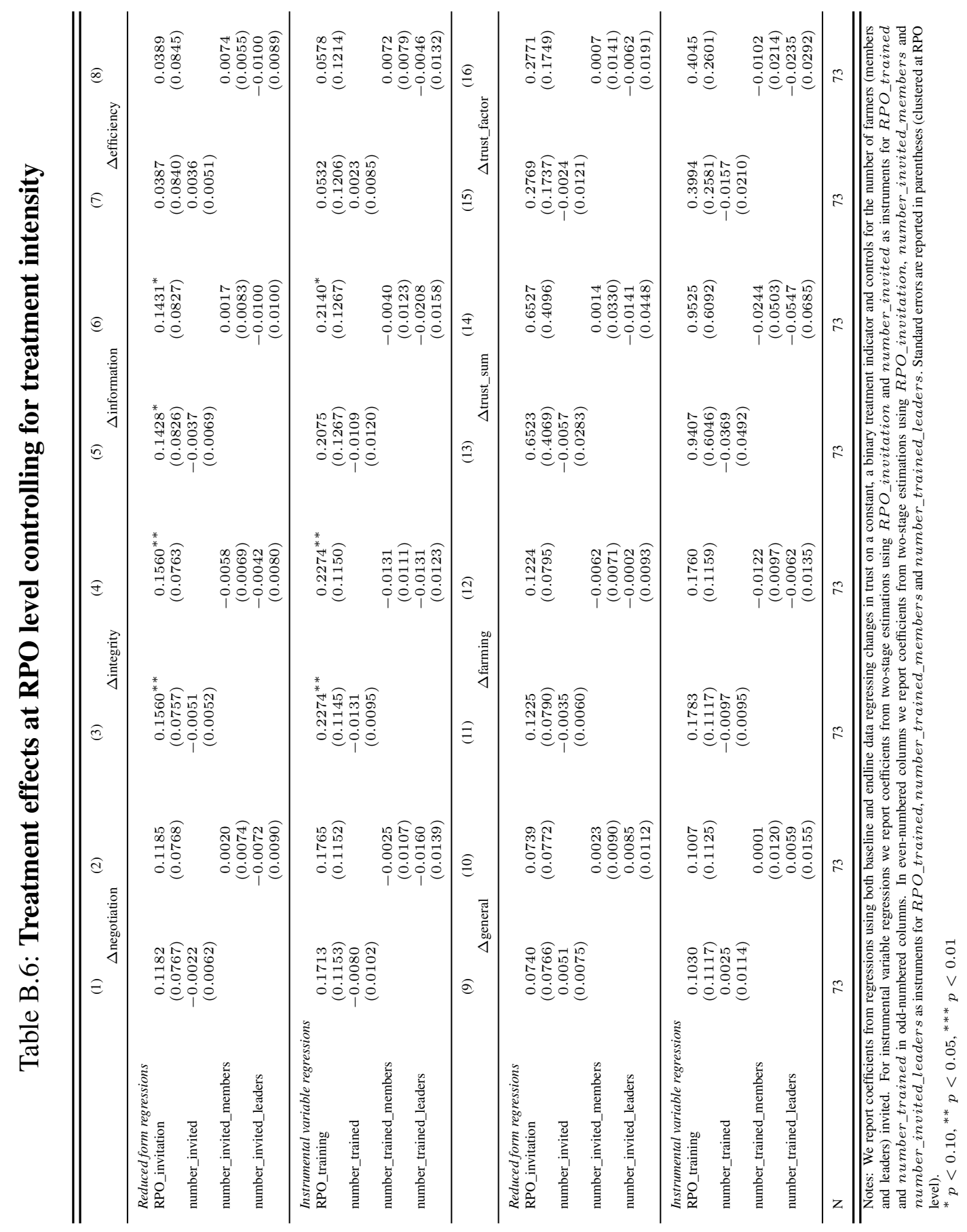


Second, we follow McKenzie (2012) who argues that large improvements in power can arise when estimating treatment effects via an Analysis of Covariance (ANCOVA) estimation compared to using the difference-in-differences specification. While difference-in-differences fully corrects for potential baseline imbalances between treatment and control groups, which may be inefficient if baseline data have little predictive power for future outcomes, ANCOVA reduces the variance of the treatment effect estimator by conditioning on a variable that is correlated with the outcome of interest. ANCOVA includes the mean value of the outcome over all available pre-treatment rounds as a covariate when estimating the treatment effect. In our case of one pre-treatment and one post-treatment survey, it includes the baseline value of the outcome as a covariate.

Thus, we regress trust at endline on a constant, a binary treatment indicator and on trust at baseline. We estimate these regressions without covariates, with controls for onion and rice cultivation (see Table B.7) and with control for the number of invited/trained persons per RPO (see Table B.8).

We use RPO_invitation as instrument for RPO_training in Table B.7 and RPO_invitation and number_invited as instruments for RPO_trained and number_trained in Table B.8. Results are similar to those from the differencein-differences estimations. Without covariates, we find a significantly positive intention-to-treat effect of 10 to 12 percentage points for trust in leaders' negotiation skills, their integrity, and their informational advantage. We find a (significantly) positive intention-to-treat effect of 11 percentage points on both measures of trust in members. The treatment effect of the training itself is again slightly larger. These results are robust to controlling for onion and rice cultivation and to controlling for the number of invitees/participants. 


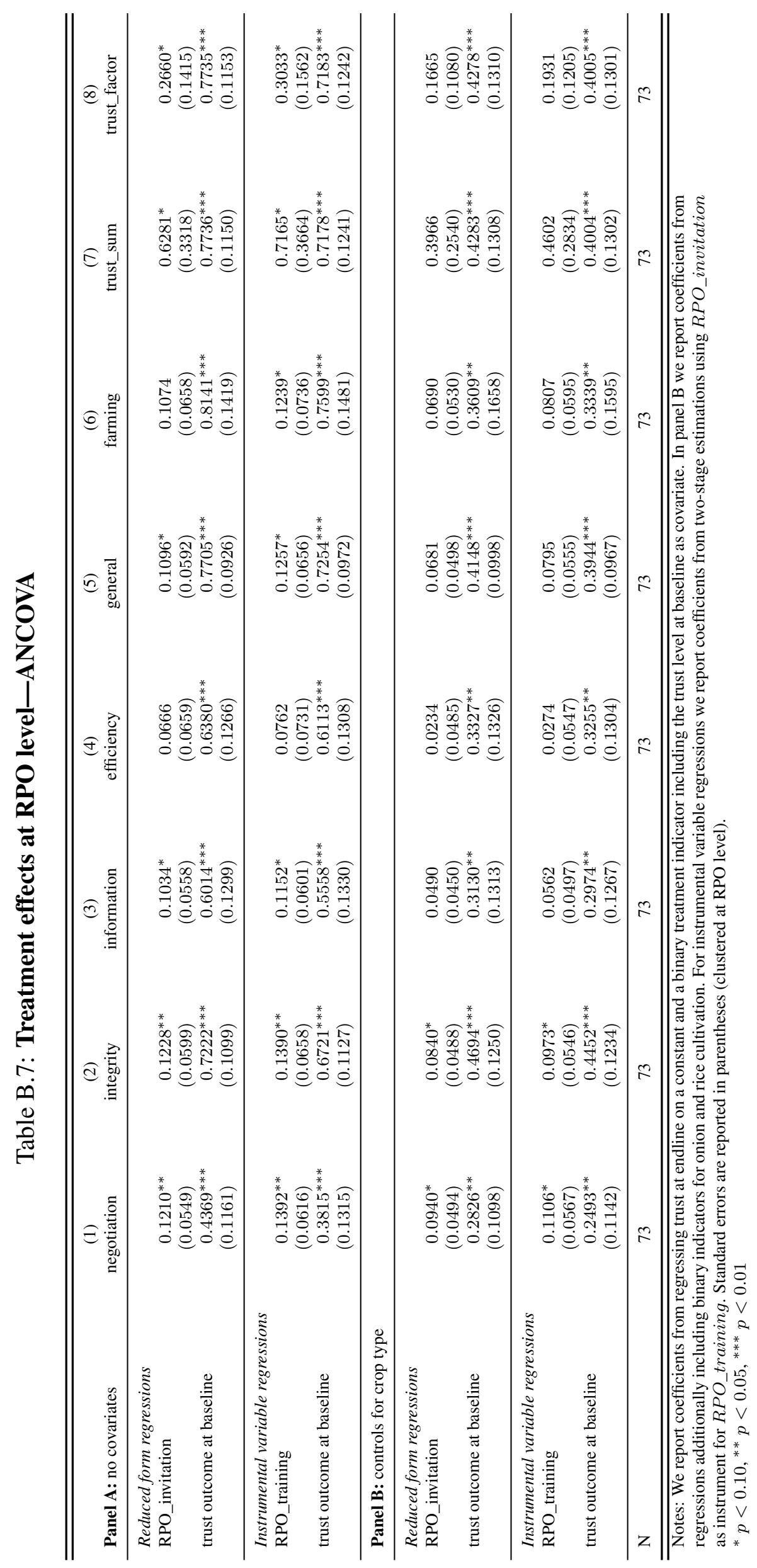




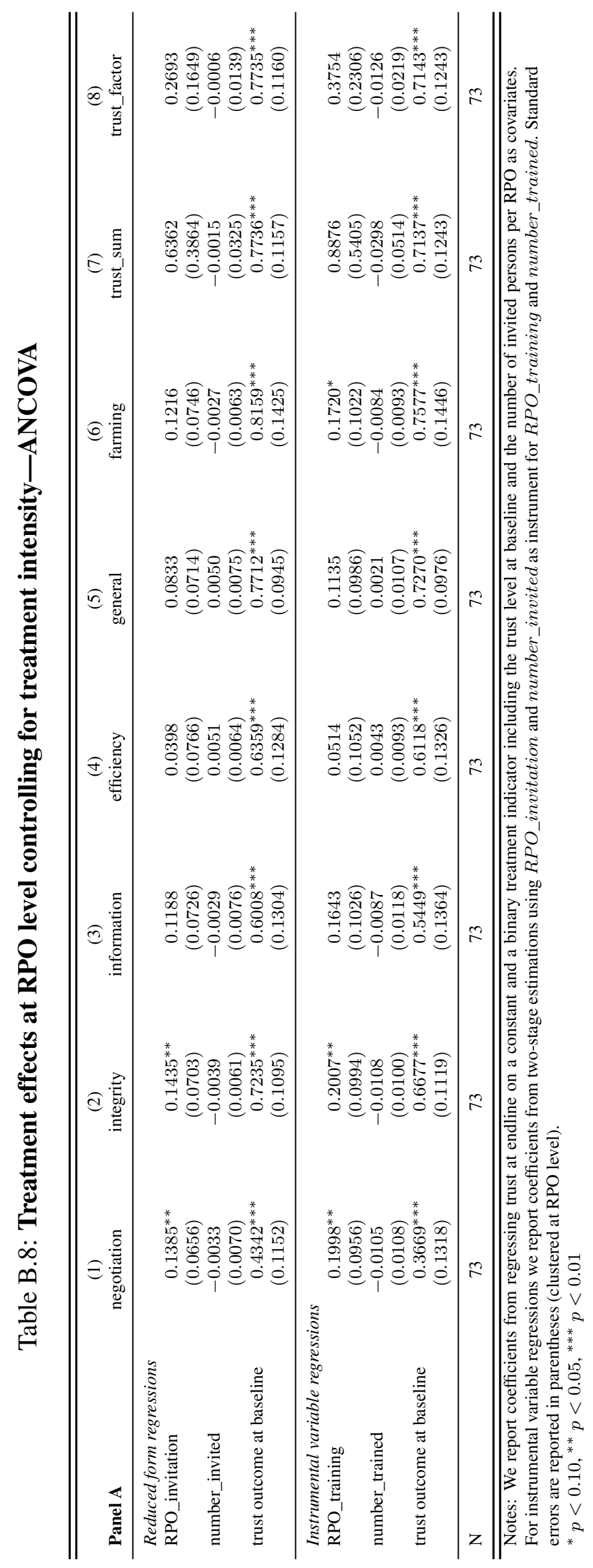




\section{B.4 Robustness checks for treatment effects on individual level}

To confirm our main findings on treatment effects on individual level presented in Section 6, we run similar robustness checks as we did for the treatment effects on RPO level.

First, using the full sample of 798 farmers, we enlarge the model in first differences (see equations (5) and (6)) by allowing for onion-specific and rice-specific time trends (see Table B.9) and by controlling for the number of invited/trained persons per RPO (see Table B.10, 37 Table B.9 shows results for regressing changes in trust on a binary treatment indicator for personal treatment, a binary indicator for treatment of others, a binary indicator for rice cultivation, a binary indicator for onion cultivation and a constant. We report both intention-to-treat effects as well as results from two-stage regressions using invitation status as an instrument for training participation. We instrument for spillover_training and personal_training using RPO_invitation and personal_invitation as instruments ${ }^{38}$ Qualitatively, results remain unchanged compared to the model in first differences without covariates. We find a significantly positive effect of having personally been invited of 13 to 18 percentage points on trust in leaders' integrity and their informational advantages as well as on both measures of trust in members. The direct treatment effect of the training is again slightly larger.

Table B.10 shows results for regressing changes in trust on a binary treatment indicator for personal treatment, a binary indicator for treatment of others, the number of invited farmers and a constant. We report both intention-to-treat effects as well as results from two-stage regressions using invitation status as an instrument for training participation. We use RPO_invitation, number_invited and personal_invitation as instruments for spillover_training, number_trained and personal_training. The highly significant correlation coefficients range between 0.2700 and 0.9004 . Qualitatively, results remain unchanged compared to the model in first differences without covariates. We find a significantly positive effect of having personally been invited of 19 to 22 percentage points on trust in leaders' integrity and their informational advantages as well as on both measures

\footnotetext{
${ }^{37}$ Note that when including covariates to the model in first differences, it is no longer equivalent to a fixed effects model.

${ }^{38}$ The highly significant correlation coefficients are 0.5702 for spillover_training and RPO_invitation, 0.2700 for personal_training and RPO_invitation, -0.3509 for personal_invitation and spillover_training and 0.7993 for personal_invitation and personal_training.
} 
of trust in members. The direct treatment effect of the training is again slightly larger.

Second, we estimate ANCOVA specifications. We regress trust at endline on a constant, a binary treatment indicator for personal treatment, a binary indicator for treatment of others, and on trust at baseline. We estimate these regressions without covariates, with controls for onion and rice cultivation (see Table B.11) and with controlling for the number of invited/trained persons per RPO (see Table B.12). In the regressions reported in Table B.11 we use RPO_invitation and personal_invitation as instruments for spillover_training and personal_training. For table B.12 we use RPO_invitation, number_invited and personal_invitation as instruments for spillover_training, number_trained and personal_training. Results are similar to those from the difference-in-differences estimations. Without covariates, we find a significantly positive treatment effect of having personally been invited of 13 to 23 percentage points for all measures of trust and indication for a spillover effect of 11 to 13 percentage points for trust in leaders' negotiation skills and their integrity. The treatment effect of the training itself is again slightly larger. Results are again robust to controlling for onion and rice cultivation and to controlling for the number of invitees/participants. 


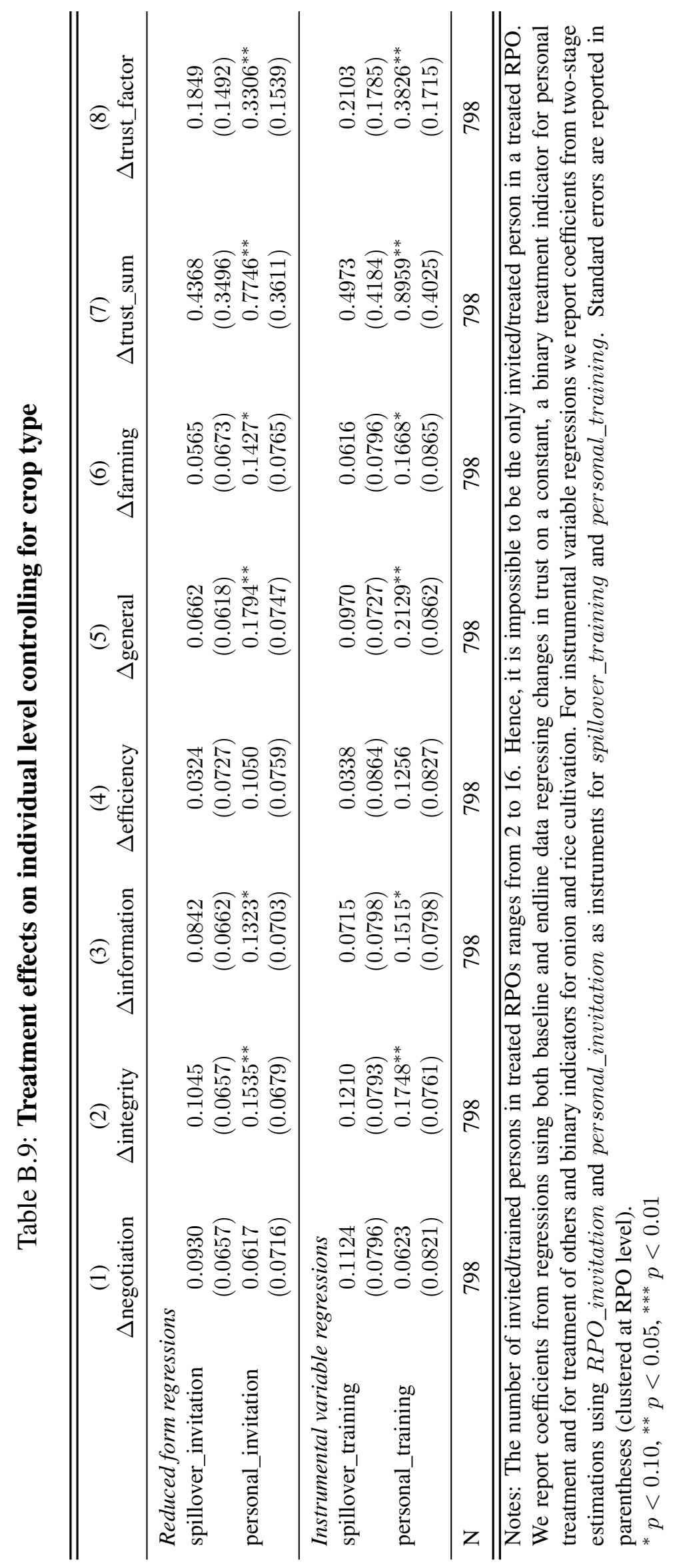




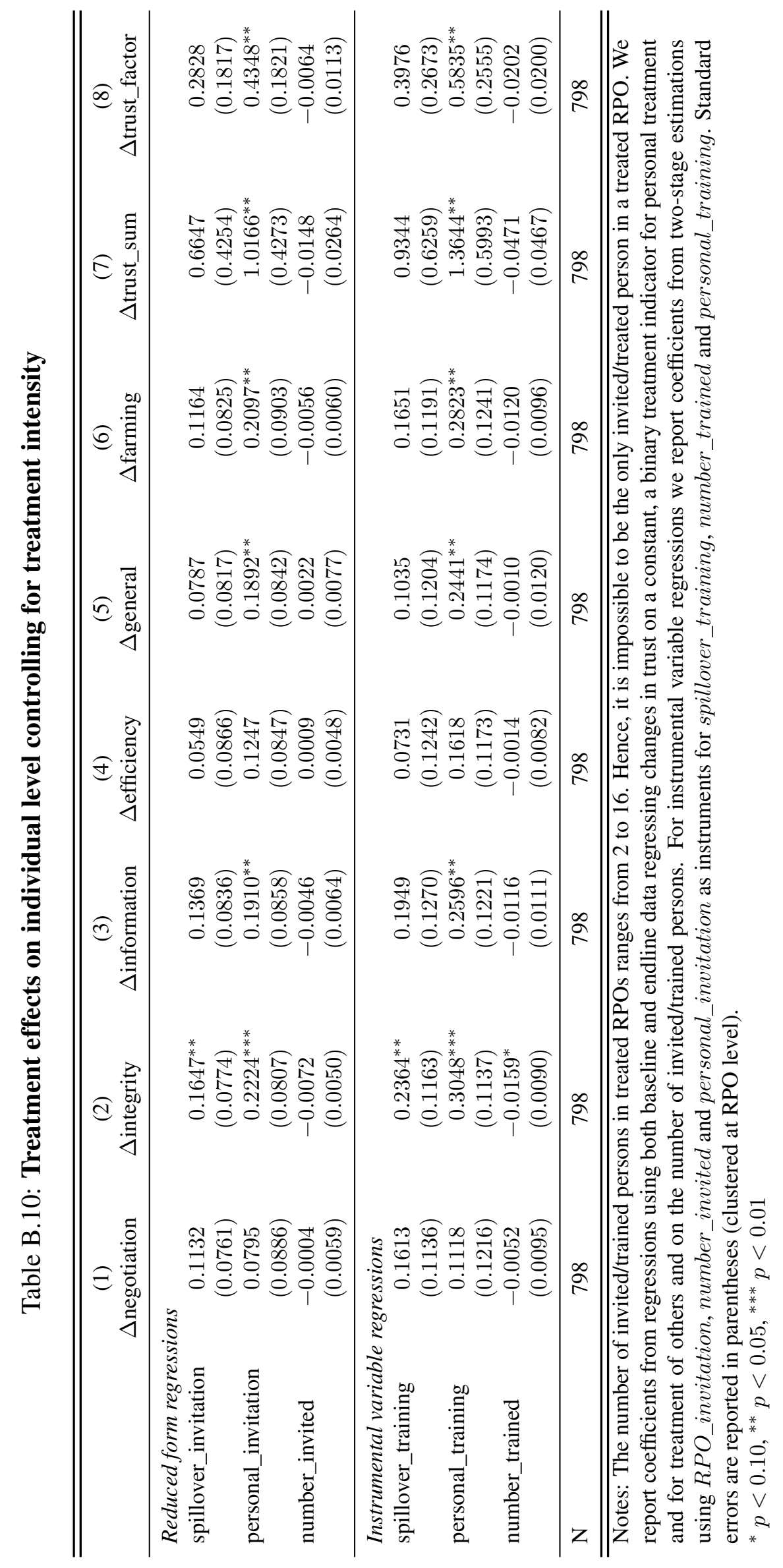




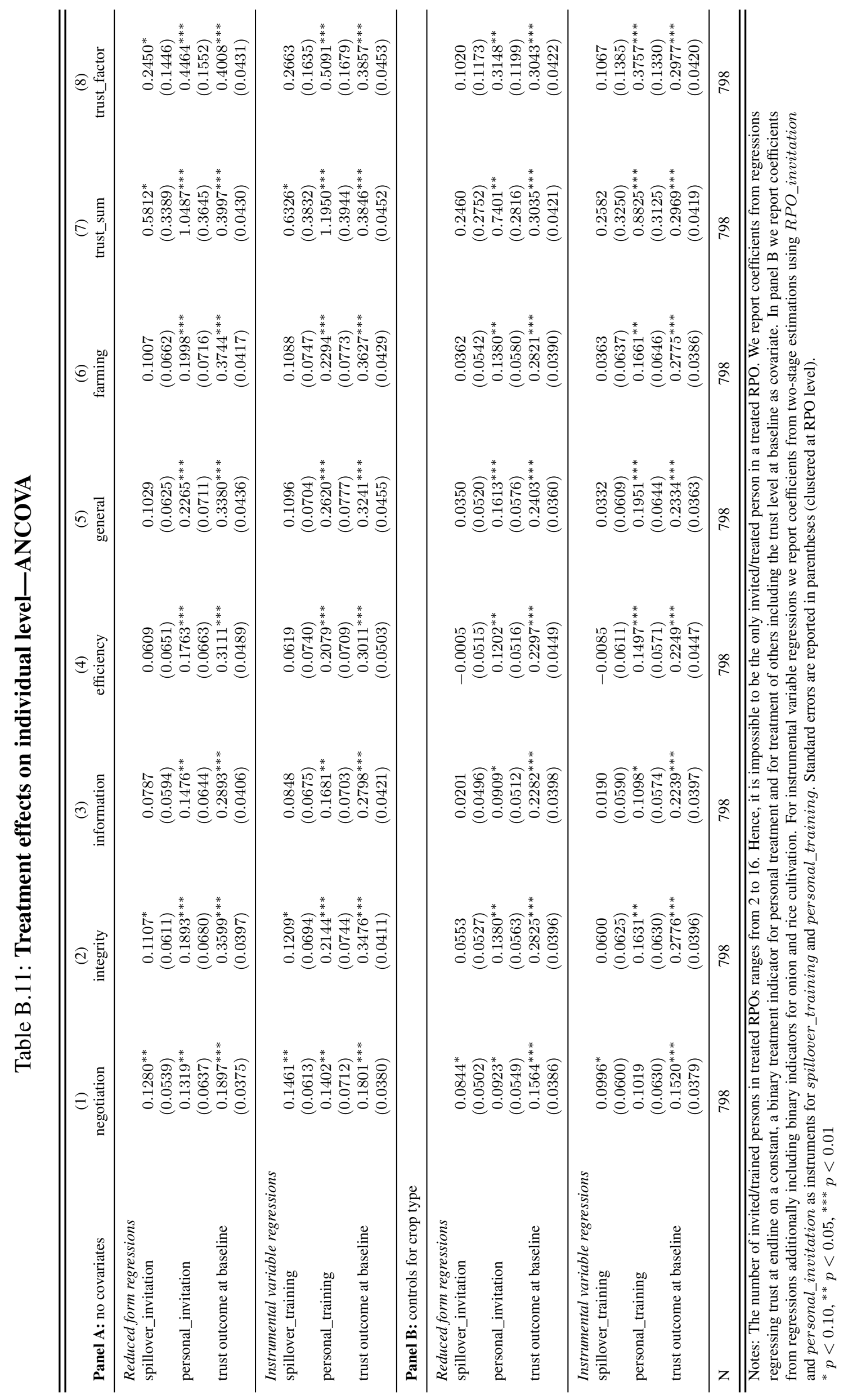




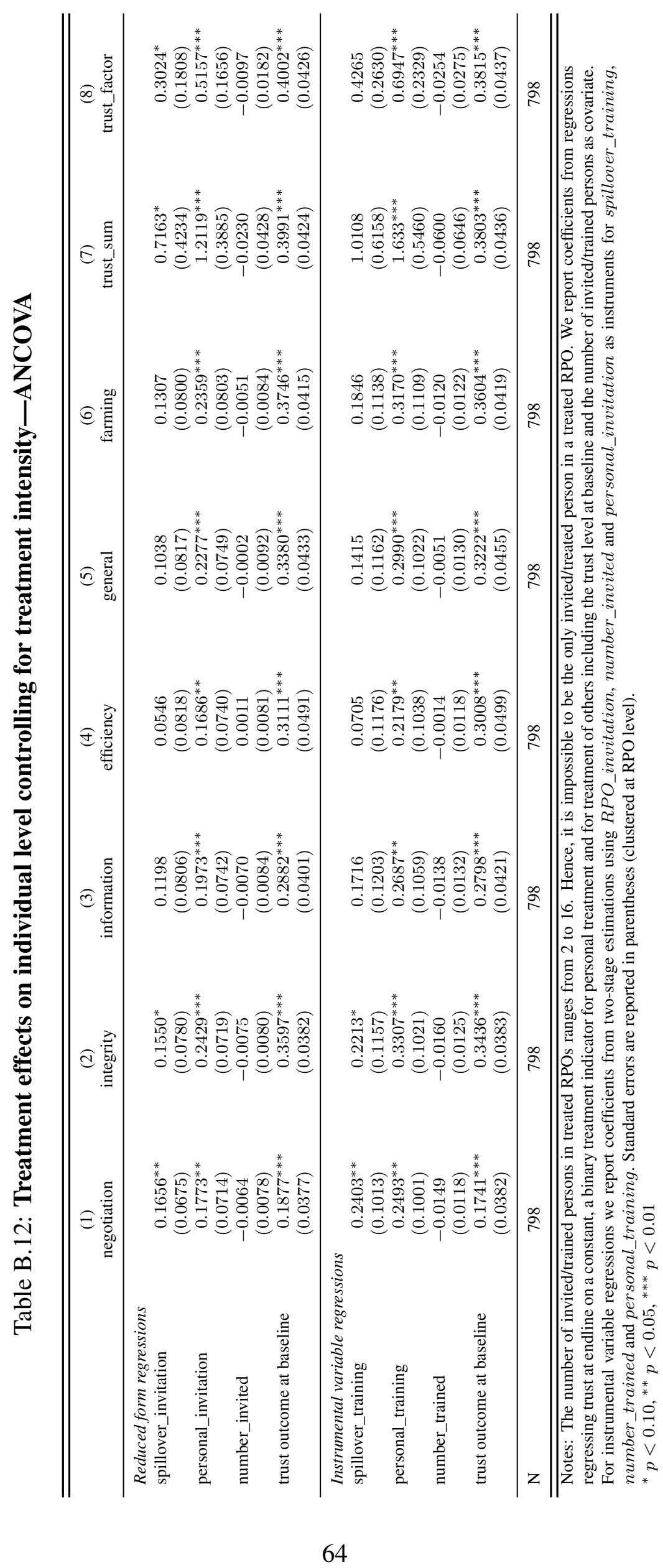

